\title{
Speech and language therapy versus placebo or no intervention for speech problems in Parkinson's disease (Review)
}

Herd CP, Tomlinson CL, Deane KHO, Brady MC, Smith CH, Sackley CM, Clarke CE

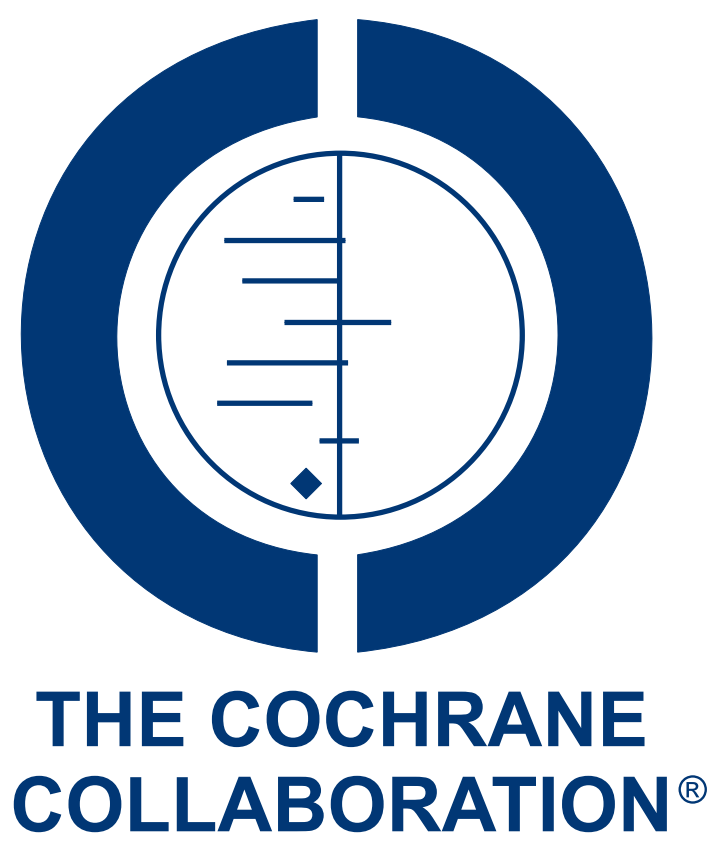

This is a reprint of a Cochrane review, prepared and maintained by The Cochrane Collaboration and published in The Cochrane Library 2012, Issue 8

http://www.thecochranelibrary.com

\section{WILEY}

Speech and language therapy versus placebo or no intervention for speech problems in Parkinson's disease (Review) Copyright $\odot 2012$ The Cochrane Collaboration. Published by John Wiley \& Sons, Ltd. 
TABLE OF CONTENTS

HEADER . . . . . . . . . . . . . . . . . . . . . . . . . . . . . . . . . . . . . . . 1

ABSTRACT . . . . . . . . . . . . . . . . . . . . . . . . . . . . . . . . . . . . . . .

PLAIN LANGUAGE SUMMARY . . . . . . . . . . . . . . . . . . . . . . . . . . . . . . . . . . . 2

BACKGROUND . . . . . . . . . . . . . . . . . . . . . . . . . . . . . . . . . . . . . 2

OBJECTIVES . . . . . . . . . . . . . . . . . . . . . . . . . . . . . . . . . . . . . . . . . . . . . . .

METHODS . . . . . . . . . . . . . . . . . . . . . . . . . . . . . . . . . . . . . . . . . . .

RESULTS . . . . . . . . . . . . . . . . . . . . . . . . . . . . . . . . . . . . . . . 4

Figure 1. . . . . . . . . . . . . . . . . . . . . . . . . . . . . . . . . . . . . 6

Figure 2. . . . . . . . . . . . . . . . . . . . . . . . . . . . . . . . . . . . . .

Figure 3. . . . . . . . . . . . . . . . . . . . . . . . . . . . . . . . . . . . . . 10

Figure $4 . \quad$. . . . . . . . . . . . . . . . . . . . . . . . . . . . . . . . . . . . . . 411

DISCUSSION . . . . . . . . . . . . . . . . . . . . . . . . . . . . . . . . . . . . .

AUTHORS' CONCLUSIONS . . . . . . . . . . . . . . . . . . . . . . . . . . . . . . . . . . . . . . .

ACKNOWLEDGEMENTS . . . . . . . . . . . . . . . . . . . . . . . . . . . . . . . . . . . . . . . . 14

REFERENCES . . . . . . . . . . . . . . . . . . . . . . . . . . . . . . . . . . . . . . 14

CHARACTERISTICS OF STUDIES . . . . . . . . . . . . . . . . . . . . . . . . . . . . . . . . . . . . . 16

DATA AND ANALYSES . . . . . . . . . . . . . . . . . . . . . . . . . . . . . . . . . . . . . . . . . . . . . . . . . . .

Analysis 1.1. Comparison 1 SLT therapy versus no SLT therapy, Outcome 1 SPL monologue pre/post. . . . . . . . 23

Analysis 1.2. Comparison 1 SLT therapy versus no SLT therapy, Outcome 2 SPL reading pre/post. . . . . . . . . . 24

Analysis 1.3. Comparison 1 SLT therapy versus no SLT therapy, Outcome 3 SPL monologue pre/6 month follow-up. 25

Analysis 1.4. Comparison 1 SLT therapy versus no SLT therapy, Outcome 4 SPL reading pre/6 month follow-up. $\quad . \quad 25$

Analysis 1.5. Comparison 1 SLT therapy versus no SLT therapy, Outcome 5 SPL sustained phonation pre/post. . . . 26

Analysis 1.6. Comparison 1 SLT therapy versus no SLT therapy, Outcome 6 SPL sustained phonation pre/ 6 month follow-

up. . . . . . . . . . . . . . . . . . . . . . . . . . . . . . . . . . . 26

Analysis 1.7. Comparison 1 SLT therapy versus no SLT therapy, Outcome 7 SPL describing picture pre/post. . . . . $\quad 27$

Analysis 1.8. Comparison 1 SLT therapy versus no SLT therapy, Outcome 8 SPL describing picture pre/6 month follow-

up. . . . . . . . . . . . . . . . . . . . . . . . . . . . . . . . . . . . . . . . . . . . 27

Analysis 1.9. Comparison 1 SLT therapy versus no SLT therapy, Outcome 9 SPL /i/. . . . . . . . . . . . . . . . $\quad$. 28

Analysis 1.10. Comparison 1 SLT therapy versus no SLT therapy, Outcome 10 SPL /u/. . . . . . . . . . . . 28

Analysis 1.11. Comparison 1 SLT therapy versus no SLT therapy, Outcome 11 SPL /a/. . . . . . . . . . . . . 29

Analysis 1.12. Comparison 1 SLT therapy versus no SLT therapy, Outcome 12 F2u. . . . . . . . . . . . . . . . . 29

Analysis 1.13. Comparison 1 SLT therapy versus no SLT therapy, Outcome 13 F2i/F2u. . . . . . . . . . . . . . 30

Analysis 1.14. Comparison 1 SLT therapy versus no SLT therapy, Outcome 14 Vowel goodness /i/. . . . . . . . . 30

Analysis 1.15. Comparison 1 SLT therapy versus no SLT therapy, Outcome 15 Vowel goodness /u/. . . . . . . . 31

Analysis 1.16. Comparison 1 SLT therapy versus no SLT therapy, Outcome 16 Vowel goodness /a/. . . . . . . . 31

Analysis 2.1. Comparison 2 Therapy with visual feedback versus no treatment, Outcome 1 SPL monologue pre/post. 32

Analysis 2.2. Comparison 2 Therapy with visual feedback versus no treatment, Outcome 2 SPL reading pre/post. $\quad . \quad 32$

Analysis 2.3. Comparison 2 Therapy with visual feedback versus no treatment, Outcome 3 Frenchay dysarthria

assessment. . . . . . . . . . . . . . . . . . . . . . . . . . . . . . . . . . . . 33

Analysis 2.4. Comparison 2 Therapy with visual feedback versus no treatment, Outcome 4 Pitch range pre/post. . . $\quad 33$

Analysis 2.5. Comparison 2 Therapy with visual feedback versus no treatment, Outcome 5 Volume range pre/post. . 34

Analysis 2.6. Comparison 2 Therapy with visual feedback versus no treatment, Outcome 6 Fundamental frequency. . 34

ADDITIONAL TABLES . . . . . . . . . . . . . . . . . . . . . . . . . . . . . . . . . . . 34

APPENDICES . . . . . . . . . . . . . . . . . . . . . . . . . . . . . . . . . . . . . . . . . . .

WHAT'S NEW . . . . . . . . . . . . . . . . . . . . . . . . . . . . . . . . . . . . . . . . . . . 40

HISTORY . . . . . . . . . . . . . . . . . . . . . . . . . . . . . . . . . . . . . . . 40

CONTRIBUTIONS OF AUTHORS . . . . . . . . . . . . . . . . . . . . . . . . . . . . . . . . . . . . . . . . . .

DECLARATIONS OF INTEREST . . . . . . . . . . . . . . . . . . . . . . . . . . . . . . . . . . . . . . . . .

SOURCES OF SUPPORT . . . . . . . . . . . . . . . . . . . . . . . . . . . . . . . . . . . . . . . . . . . . . .

INDEX TERMS . . . . . . . . . . . . . . . . . . . . . . . . . . . . . . . . . . . . 41

Speech and language therapy versus placebo or no intervention for speech problems in Parkinson's disease (Review)

Copyright @ 2012 The Cochrane Collaboration. Published by John Wiley \& Sons, Ltd. 


\title{
[Intervention Review]
}

\section{Speech and language therapy versus placebo or no intervention for speech problems in Parkinson's disease}

\author{
Clare P Herd ${ }^{1}$, Claire L Tomlinson ${ }^{2}$, Katherine HO Deane ${ }^{3}$, Marian C Brady ${ }^{4}$, Christina H Smith ${ }^{5}$, Catherine M Sackley ${ }^{6}$, Carl E \\ Clarke $^{1}$ \\ ${ }^{1}$ School of Clinical and Experimental Medicine, College of Medical and Dental Sciences, Birmingham, UK. ${ }^{2}$ Birmingham Clinical \\ Trials Unit, University of Birmingham, Birmingham, UK. ${ }^{3}$ Edith Cavell Building, University of East Anglia, Norwich, UK. ${ }^{4} \mathrm{Nursing}$, \\ Midwifery and Allied Health Professions Research Unit, Glasgow Caledonian University, Glasgow, UK. ${ }^{5}$ Psychology and Language \\ Sciences, University College London, London, UK. ${ }^{6}$ Faculty of Medicine and Health Sciences, University of East Anglia, Norwich, \\ UK
}

Contact address: Carl E Clarke, School of Clinical and Experimental Medicine, College of Medical and Dental Sciences, University of Birmingham, Edgbaston, Birmingham, B15 2TT, UK. c.e.clarke@bham.ac.uk.

Editorial group: Cochrane Movement Disorders Group.

Publication status and date: New search for studies and content updated (no change to conclusions), published in Issue 8, 2012.

Review content assessed as up-to-date: 11 April 2011.

Citation: Herd CP, Tomlinson CL, Deane KHO, Brady MC, Smith CH, Sackley CM, Clarke CE. Speech and language therapy versus placebo or no intervention for speech problems in Parkinson's disease. Cochrane Database of Systematic Reviews 2012, Issue 8. Art. No.: CD002812. DOI: 10.1002/14651858.CD002812.pub2.

Copyright (C) 2012 The Cochrane Collaboration. Published by John Wiley \& Sons, Ltd.

\begin{abstract}
A B S T R A C T
Background

Parkinson's disease patients commonly suffer from speech and vocal problems including dysarthric speech, reduced loudness and loss of articulation. These symptoms increase in frequency and intensity with progression of the disease). Speech and language therapy (SLT) aims to improve the intelligibility of speech with behavioural treatment techniques or instrumental aids.
\end{abstract}

Objectives

To compare the efficacy of speech and language therapy versus placebo or no intervention for speech and voice problems in patients with Parkinson's disease.

Search methods

Relevant trials were identified by electronic searches of numerous literature databases including MEDLINE, EMBASE, and CINAHL, as well as handsearching of relevant conference abstracts and examination of reference lists in identified studies and other reviews. The literature search included trials published prior to $11^{\text {th }}$ April 2011.

\section{Selection criteria}

Only randomised controlled trials (RCT) of speech and language therapy versus placebo or no intervention were included.

Data collection and analysis

Data were abstracted independently by $\mathrm{CH}$ and $\mathrm{CT}$ and differences settled by discussion.

Speech and language therapy versus placebo or no intervention for speech problems in Parkinson's disease (Review)

Copyright @ 2012 The Cochrane Collaboration. Published by John Wiley \& Sons, Ltd. 


\section{Main results}

Three randomised controlled trials with a total of 63 participants were found comparing SLT with placebo for speech disorders in Parkinson's disease. Data were available from 41 participants in two trials. Vocal loudness for reading a passage increased by $6.3 \mathrm{~dB}$ $(\mathrm{P}=0.0007)$ in one trial, and $11.0 \mathrm{~dB}(\mathrm{P}=0.0002)$ in another trial. An increase was also seen in both of these trials for monologue speaking of $5.4 \mathrm{~dB}(\mathrm{P}=0.002)$ and $11.0 \mathrm{~dB}(\mathrm{P}=0.0002)$, respectively. It is likely that these areclinically significant improvements. After six months, patients from the first trial were still showing a statistically significant increase of $4.5 \mathrm{~dB}(\mathrm{P}=0.0007)$ for reading and $3.5 \mathrm{~dB}$ for monologue speaking. Some measures of speech monotonicity and articulation were investigated; however, all these results were non-significant.

\section{Authors' conclusions}

Although improvements in speech impairments were noted in these studies, due to the small number of patients examined, methodological flaws, and the possibility of publication bias, there is insufficient evidence to conclusively support or refute the efficacy of SLT for speech problems in Parkinson's disease. A large well designed placebo-controlled RCT is needed to demonstrate SLT's effectiveness in Parkinson's disease. The trial should conform to CONSORT guidelines. Outcome measures with particular relevance to patients with Parkinson's disease should be chosen and patients followed for at least six months to determine the duration of any improvement.

\section{PLAIN LANGUAGESUMMARY}

\section{Speech and language therapy for speech problems in Parkinson's disease}

Many people with Parkinson's disease suffer from disorders of speech. The most frequently reported speech problems are weak, hoarse, nasal or monotonous voice, imprecise articulation, slow or fast speech, difficulty starting speech, impaired stress or rhythm, stuttering and tremor. People with the condition also tend to give fewer non-verbal cues, such as facial expressions and hand gestures. These disabilities tend to increase as the disease progresses and can lead to serious problems with communication.

This review compared the benefits of speech and language therapy versus placebo (sham therapy) or no treatment for speech disorders in Parkinson's disease. Relevant trials were identified by electronic searches of 16 medical literature databases, various registers of clinical trials and an examination of the reference lists of identified studies and other reviews.

Only randomised controlled trials were included in this review. These were studies where two groups of patients were compared, one group had speech and language therapy, the other did not receive any therapy intended to improve speech. The patients were assigned to each of the groups in a random fashion so as to reduce the potential for bias.

Three trials with a total of 63 patients were found comparing speech and language therapy with an untreated group. The quality of the methods used in these trials was variable, with all studies failing in at least one critical area. All three of the controlled trials reported a positive effect of speech and language therapy for speech disorders in Parkinson's disease. Many of the outcome measures examined appeared to improve by a clinically significant amount after therapy. However, it should be noted that there were flaws in the methods used in these studies and only a small number of patients with Parkinson's disease were examined. This means that there is insufficient evidence to absolutely prove or disprove the benefit of speech and language therapy for the treatment of speech disorders in Parkinson's disease patients, but lack of evidence does not mean lack of effect.

A large well designed placebo-controlled randomised trial is needed to assess the effectiveness of speech and language therapy for speech disorders in Parkinson's disease. Outcome measures with particular relevance to people with Parkinson's disease should be chosen and the patients followed for at least six months to determine the duration of any improvement.

\section{B A C K G R O U N D}

For definition of terms see Table 1. Glossary
Speech problems are common in Parkinson's disease and increase in frequency and intensity with progression of the disease (Streifler

Speech and language therapy versus placebo or no intervention for speech problems in Parkinson's disease (Review) 
1984; Sapir 2001). Dysarthria is a collective name for a group of speech disorders resulting from disturbances in muscular control of the speech mechanism due to damage of the central nervous system. It designates problems in oral communication due to paralysis, weakness or incoordination of the speech musculature (Darley 1969). Common characteristics of Parkinsonian dysarthria are monotony of pitch and volume (dysprosody), reduced stress, imprecise articulation, variations in speed resulting in both inappropriate silences and rushes of speech, and a breathy hoarseness to the speech (hypophonia) reflecting the difficulty the patient has in synchronising talking and breathing (Logemann 1978; Stewart 1995). Many of these features are attributed to hypokinesia (paucity of movement) and rigidity which are considered to be cardinal features of Parkinson's disease (Mawdsley 1971). Parkinson's disease patients also suffer from cognitive impairment which leads to difficulties in language selection, language understanding, coordination and dual tasks (talking and walking) as well as emotional intent and understanding. These issues do not come under the umbrella of dysarthric speech but impact on the ability of individuals to participate in spoken communication. As a result it was decided that the title of this review should be changed from 'dysarthria' to include the full complexity of 'speech problems in Parkinson's disease'.

Four approaches to speech therapy are available: behavioural treatment techniques (drill, exercise), instrumental aids including prosthetic and augmentative devices, medication, and surgical procedures. Pharmacotherapy and surgery have a limited role in the management of specific motor impairments such as speech disorders, particularly those that emerge during later stages of the disease. It has been suggested that the behavioural treatment techniques of speech and language therapy (SLT) may be more effective in improving the intelligibility of speech in Parkinson's disease. Even then, "compensated intelligibility" rather than "normal speech" may be considered the more limited goal of SLT (Rosenbek 1985).

A 2009 patient survey by Parkinson's UK showed that only 34\% of patients with Parkinson's disease in England reported receiving SLT (Parkinson's disease society 2008). This low referral rate does not accord with the advice in most published guidelines which suggests that SLT should always be made available for the management of Parkinson's disease (NCC-CC 2006).

This review compared the efficacy of speech and language therapy with placebo or no intervention for speech problems in patients with Parkinson's disease. Another review will examine trials that compare two forms of SLT techniques.

\section{O B J E C T I V E S}

To compare the efficacy of speech and language therapy versus placebo or no intervention for speech problems in patients with
Parkinson's disease.

\section{METHODS}

\section{Criteria for considering studies for this review}

\section{Types of studies}

All randomised controlled trials comparing speech and language therapy with placebo or no intervention were considered for inclusion in the study. Both random and quasi-random methods of allocation were allowed.

\section{Types of participants}

- Patients with a diagnosis of Parkinson's disease (as defined by the authors of the studies).

- Any duration of Parkinson's disease.

- All ages.

- Any drug therapy.

- Any duration of treatment.

\section{Types of interventions}

Speech and language therapy, placebo or no intervention.

\section{Types of outcome measures}

1. Speech and voice production parameters (i.e. measures of impairment):

(a) total impairments (dysarthria rating scale, intelligibility rating scale);

(b) objective and subjective acoustic measures of speech samples (pitch, loudness, sentence length etc.);

(c) measures of laryngeal activity (fibre optic laryngoscopy, stroboscopy);

(d) level of communication participation.

2. Activities of daily living (e.g. Sickness Impact Profile (SIP) communication subsection).

3. Handicap and quality of life measures, both disease specific (e.g. Parkinson's Disease Questionnaire - 39, (PDQ39)) and generic (e.g. Short Form - 36, (SF36)).

4. Depression rating scales (e.g. Beck Depression Index, (BDI)).

5. Adverse effects.

6. Carer outcomes (e.g. carer strain index).

7. Economic analysis.

We examined both short-term and long-term effects of the intervention. 


\section{Search methods for identification of studies}

1. The review is based on the search strategy of the Cochrane Movement Disorders Group and also the following more general search strategy:

a. Dysarthria OR speech OR speak OR intelligibility OR dysprosody OR hypophonia OR monotonicity OR phonate

b. ((Speech OR speak OR language OR voice OR vocal OR articulate OR sing) near (task OR therapy OR treatment OR train OR counsel OR intervention OR exercise OR drill OR rehabilitation)) OR silverman OR LSVT

c. Parkinson OR Parkinson's disease OR Parkinsonism

d. (\#a AND \#b AND \#c) OR (\#a and \#c)

See Appendix 1 for sample search (MEDLINE). This strategy was adapted for each electronic database.

Relevant trials were identified by electronic searches of general biomedical and science databases: MEDLINE (1966 to 2011), PubMed (2010 to 2011) EMBASE (1974 to 2011), CINAHL (1982 to 2011), ISI-SCI ((1981 to 2011); rehabilitation databases: AMED (1985 to 2011), MANTIS (1880 to 2000), REHABDATA (1956 to 2011), REHADAT, GEROLIT (1979 to 2011); English language databases of foreign language research and third world publications: Pascal (1984 to 2000), LILACS (1982 to 2011), MedCarib (17th Century to 2000), Journal@rchive (19th century to 2011), AIM (1993 to 2000), IMEMR (1984 to 2011) and handsearching of appropriate conference proceedings. Relevant trials were included on the Group's specialised register of randomised controlled trials.

2. The Cochrane Central Register of Controlled Trials (CENTRAL), the CenterWatch Clinical Trials listing service, controlled-trials.com, ClinicalTrials.gov, RePORT, PEDro, NIDRR and NRR, were also searched for relevant trials.

3. The reference lists of located trials and review articles were searched.

4. Grey literature (e.g. conference abstracts, theses and internal reports) were searched. This included The International Congress on Parkinson's disease (1999, 2001), The International Congress of Parkinson's Disease and Movement Disorders (1990, 1992, 1994 , 1996 to 1998, 2002, 2004 to 2011), The American Academy of Neurology 51st annual meeting (1999) and the Congress of the European Federation of Neurological Societies (2003 to 2010). The following grey literature databases were searched: OpenSIGLE (1980 to 2011), ISI-ISTP (1982 to 2000), Proquest (1999 to 2011), Conference Papers Index (1982 to 2011) Ethos (1970 to 2011) and Index to Theses (1716 to 2011).

Further details on this search strategy are available in the Group's module within The Cochrane Library (www.cochrane.org). This includes explanations of the acronyms, sources and websites.

\section{Data collection and analysis}

The review authors (CH, CT and CEC) independently assessed the studies identified by the search strategy. Disagreements about inclusions were resolved by discussion.

We contacted authors in the cases where further trial information was required for full analysis. Full papers were assessed for methodological quality by recording the method of randomisation and blinding, whether an intention-to-treat analysis was used, if an apriori sample size calculation had been done, whether any selective reporting was apparent, the credibility of the placebo used and the similarity of the patients baseline characteristics as well as any loss to follow up. In addition we assessed whether patients remained on a stable drug regimen throughout the treatment period and follow-up, and if not whether any changes were fully disclosed.

Two authors (CH and $\mathrm{CT}$ ) abstracted data onto standardised forms independently, checked them for accuracy and amalgamated the results. Disagreements about inclusions were resolved by discussion.

We combined the results of each trial using standard meta-analytic methods (fixed-effect model) to estimate an overall effect for speech and language therapy intervention versus no intervention. All relevant outcomes were continuous variables: for these the mean difference between treatment arms was calculated using weighted mean difference methods (Fleiss 1993). In summary, this involved for each trial, calculating the mean change (and standard deviation) from baseline to the post intervention time point for both the intervention and no intervention groups. The mean difference and its variance between arms for each trial could then be calculated. In some studies the standard deviation for the mean change was not reported. In these cases we imputed this standard deviation using the standard deviations for the baseline and final scores. To do this we used the following formula to estimate the variance of the change in score:

var diff $=\operatorname{var}_{\text {pre }}+\operatorname{var}_{\text {post }}-2 \mathrm{r} \sqrt{ }\left(\operatorname{var}_{\text {pre }} \operatorname{var}_{\text {post }}\right)$

where var diff is the variance of the change score; var pre is the variance of the baseline score; var post is the variance of the final score and $\mathrm{r}$ is the correlation between the pre- and post-treatment scores. We assumed a correlation coefficient of 0.5 , which is a conservative estimate, to reduce the chance of false positive results (Higgins 2011).

These values were then combined using weighted mean difference methods to give the overall pooled estimate of the mean difference, with $95 \%$ confidence interval, for speech and language therapy versus no therapy (control). A result with a value of $\mathrm{P}<0.05$ was considered to be statistically significant.

\section{R E S U L S}

\section{Description of studies}

See: Characteristics of included studies; Characteristics of excluded studies; Characteristics of ongoing studies. 
See Table 2: Characteristics of Included Studies and Figure 1 for PRISMA flow chart.

Three randomised controlled trials were found comparing speech and language therapy with placebo for speech disorders in Parkinson's disease. A total of 63 patients were examined. 
Figure I. PRISMA flow diagram.

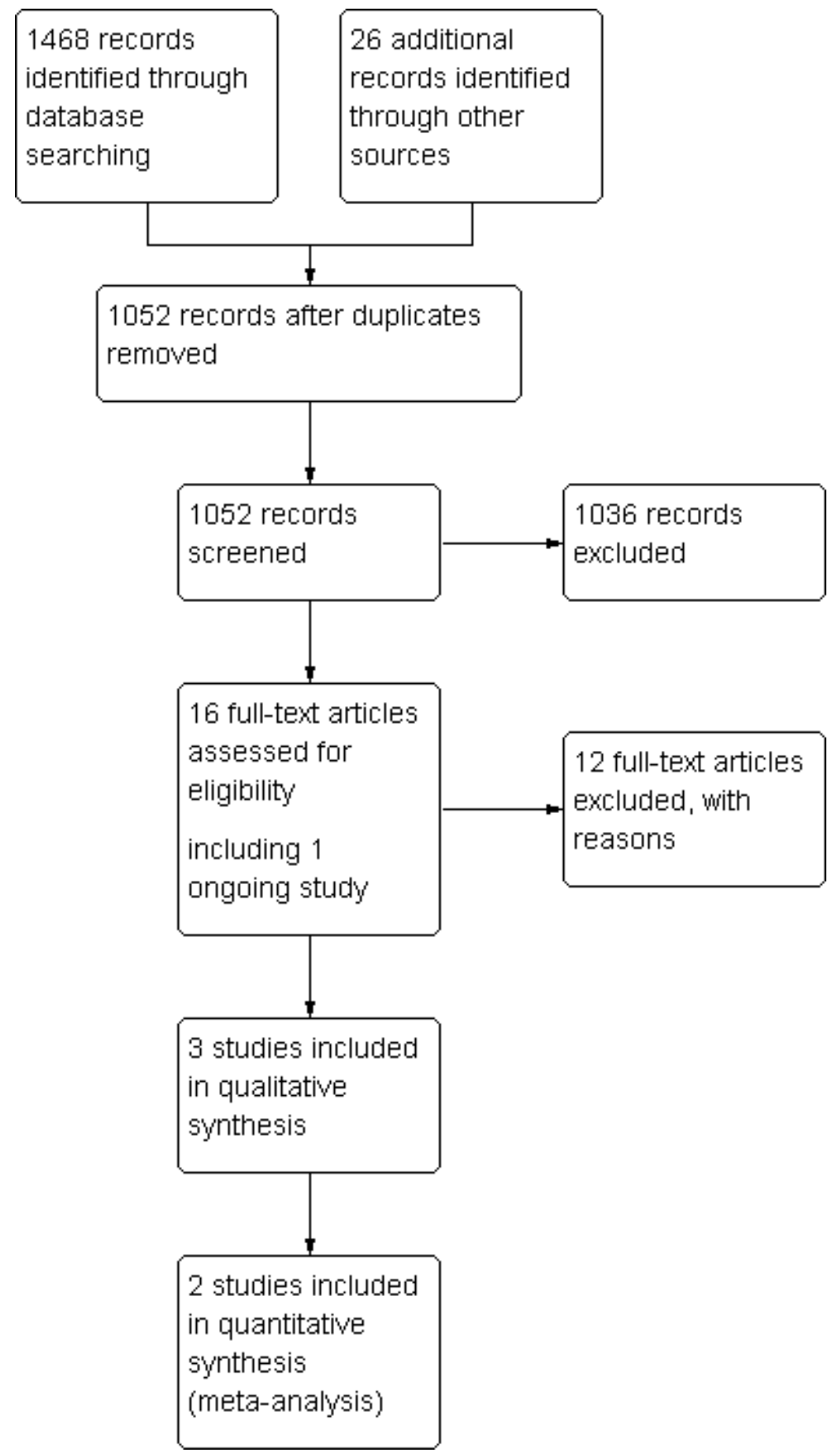




\section{TRIAL DESIGN}

All trials were parallel group, single centre studies.

PARTICIPANTS

Johnson 1990's and Ramig 2001's baseline characteristics for both treatment and placebo groups had a high degree of similarity between the groups. Robertson 1984 did not give the data on the four withdrawals, all of whom were in the control group. There was a difference of 10 years in the mean age of the two groups in this study.

\section{INTERVENTIONS}

There were significant differences in the duration and intensity of the therapy given to the patients. Johnson 1990 treated their patients for 10 hours over four weeks, Ramig 2001 treated for 16 hours over four weeks and Robertson 1984 treated for 35 to 40 hours over two weeks. All studies were conducted in an outpatient setting.

The methods of SLT differed in all of the trials. Johnson 1990 gave the patients individual therapy with the emphasis placed on prosodic features of pitch and volume. Therapy was reinforced with the use of a number of visual feedback systems. Robertson 1984 also aimed therapy at improving loudness and pitch variation but they also worked on respiration, voice production and intelligibility. Like Johnson 1990, they used visual feedback to reinforce the therapy, however, most of this therapy was carried out in a group setting with individual interventions carried out only where needed. The therapy in Ramig 2001 aimed to maximize phonatory effort and loudness during speech with improved vocal fold adduction and overall laryngeal muscle activation and was carried out on an individual basis. This method was referred to as Lee Silverman Voice Therapy (LSVT).

CONTROL DESIGN

None of the three trials provided a description of the control intervention. In personal communications with the authors of Ramig 2001 and Johnson 1990 they stated that their control group was untreated. It is assumed that this was also the case in Robertson
1984 but we were unable to contact the authors to confirm this. OUTCOME MEASURES

Robertson 1984 provided no raw data on any outcome measure, and neither was this available from the authors. Ramig 2001 reports the volume (synonymous to sound pressure level and loudness - see Glossary Table 1) of various modes of speech as well as measures of vowel articulation, including vowel formant frequencies and perceptual ratings of vowel goodness. The sound pressure level for reading a standard passage (the Rainbow passage) and for a monologue was comparable with the volume measured for these two activities in Johnson 1990's study. Johnson 1990 also gave an overall assessment of speech quality using the Frenchay Dysarthria Assessment and of the pitch of the speech in the measure of fundamental frequency.

Ramig 2001 was the only study to carry out an extended follow-up to determine the longevity of any improvements. Measurements of volume were repeated for all patients six months after treatment. EXCLUDED STUDIES

See Table: Characteristics of Excluded Studies.

We found twelve other trials and obtained the full papers to evaluate suitability of the trials for this review. Corte 2009 was a focus group trial. Wang 2008 and Wohlert 2004 did not adequately randomise participants. Trials Evans 2006; Scott 1984 and Silverman 2006 had no control group while Quedas 2007 used a healthy control group. Aguiar 2009 was a multidisciplinary trial with no data available solely from SLT component and Katsikitis 1996 and Patti 1996 concentrated on physiotherapeutic outcomes and did not report and measures of speech. No information was available for Cotter 2003 and Sapir 2007 was excluded due to incomplete overlap with Ramig 2001.

\section{Risk of bias in included studies}

See Table 2 and Figure 2 for summary of the methodological quality of the trials. 
Figure 2. Risk of bias summary: review authors' judgements about each risk of bias item for each included study.

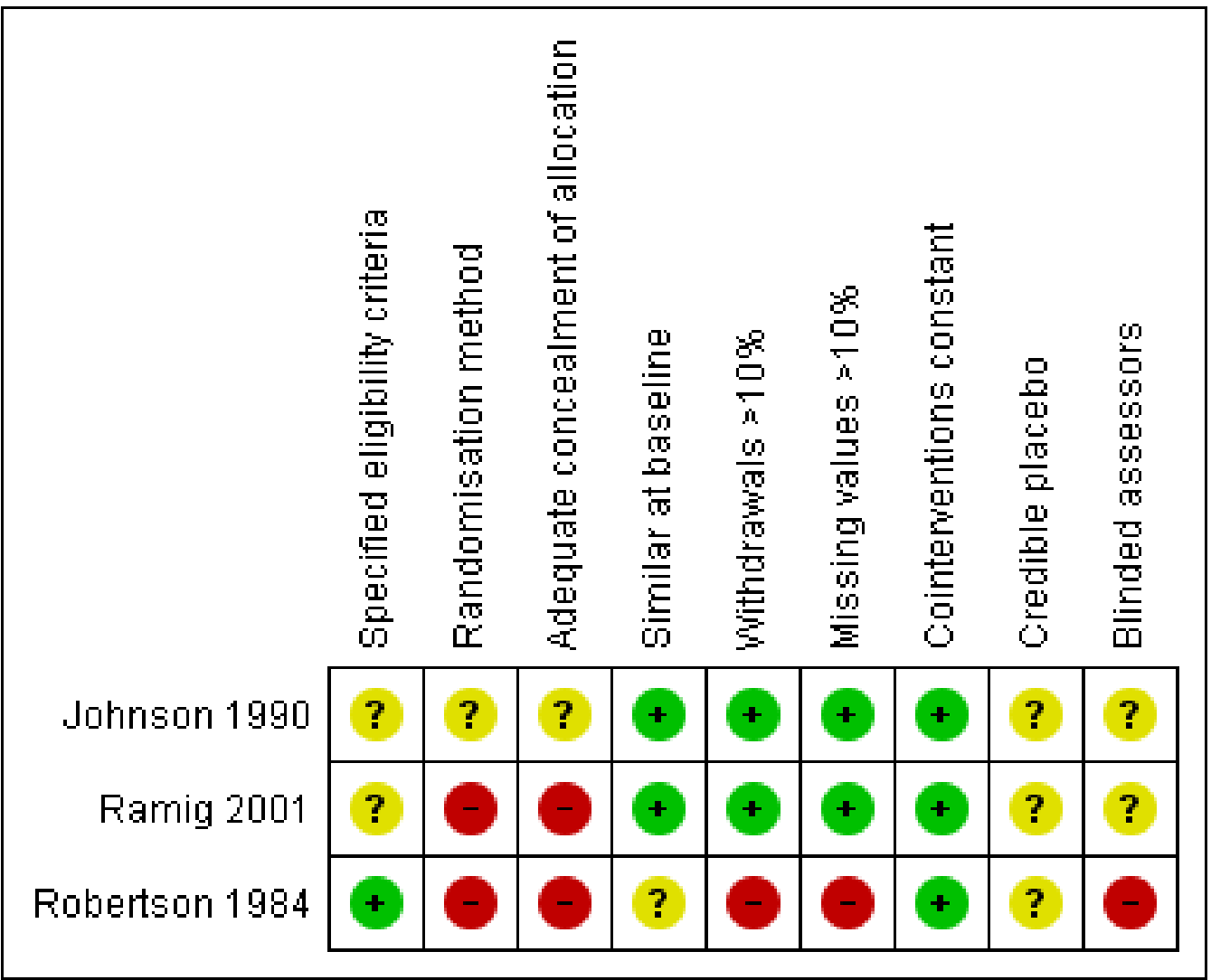

Blinding of patients and treating therapists in trials examining the efficacy of SLT is not possible in practice. This leaves such trials open to performance and attrition bias. Performance bias could be due to factors such as the patients in the therapy group performing better due to placebo and Hawthorn effects, whilst attrition bias could be due to patients in the placebo group potentially being more likely to withdraw from the trial due to disappointment at not being placed in the active therapy arm. One study (Johnson 1990) used blinded raters which reduces the potential for detection bias. Ramig 2001 offered treatment to everyone in the control arm at the end of the follow-up period: this may have reduced the potential for withdrawal from this arm of the trial.

RANDOMISATION METHOD AND CONCEALMENT OF ALLOCATION

Robertson 1984 used alternate allocation to randomise, which is not a truly random method. Ramig 2001 used a 'numbers pulled out of a hat' method of randomisation. Concealment of allocation cannot be confirmed when using such methods, thus selection bias cannot be excluded. Johnson 1990 did not state their method of randomisation or concealment of allocation (see Glossary Table

1).

\section{ELIGIBILITY CRITERIA}

The eligibility criteria for the trials were broad. Johnson 1990 did not state any eligibility criteria although it is implicit in the report that they only treated patients with Parkinson's disease. Ramig 2001 required that all individuals in their Parkinson's disease groups had adequate hearing for daily communication and were on a stable drug regime. Robertson 1984's inclusion criteria stated that the participants must have Parkinson's disease and be on a stable drug regime.

It is vital that eligibility criteria are well defined so that it is understood what sort of a population were treated. For example, it is important that the Parkinson's disease accords with the UK Brain Bank Parkinson's Disease criteria (Gibb 1988), otherwise it is more likely that individuals with Parkinson's plus syndromes will be included which have a significantly different clinical course compared to idiopathic Parkinson's disease.

None of the trials stated explicitly that their patients had a speech deficit. However, it is highly unlikely that individuals were referred 
for therapy unless they had some form of speech problem. Defining the severity of the speech problem would have enabled an assessment of which patients benefit most from the therapy.

\section{PARTICIPANT NUMBERS}

A total of 63 patients were examined. With such a small number of participants, it is unlikely that they were truly representative of the Parkinsonian population as a whole. Overall only 18 of the 63 patients examined were female (29\%), which introduces difficulties when trying to extrapolate the results of these trials to the general Parkinson's population.

SIMILARITY AT BASELINE

Considering the small number of patients in all of the studies, the likelihood of an unequal distribution is high, as demonstrated by the Robertson 1984 study where the two groups differed in their mean age by 10 years. Differences like this suggest that the method of randomisation used was unsuitable.

The baseline characteristics of those patients who withdrew were not given in Robertson 1984. Considering that the characteristics of these four individuals may have contributed to their withdrawal from the trial, it is important that this information should be available.

Only Ramig 2001 gave an indication of the severity of Parkinson's disease within the groups. This makes it difficult to judge which patients would benefit most from the therapy and whether the results are generalized across the international Parkinson's disease population. It is accepted that the Hoehn and Yahr score assesses physical disability and does not have a speech component; however, it has been shown that impairment in speaking ability increases in frequency and intensity with the progression of the disease (Sapir 2001; Streifler 1984Sapir 2001).

DESCRIPTION OF SPEECH AND LANGUAGE THERAPY

The methods of speech and language therapy were broadly described in the study publications. Ramig 2001 provided a reference to a book (Ramig 1995) that describes the LSVT method in greater depth. Johnson 1990 provided a schedule of events for each of the ten therapy sessions. Robertson 1984 provided a brief description of the activities carried out during their therapy sessions. It is important that sufficient detail is provided so that the method of therapy can be repeated by other speech and language therapists.

The drug therapy of the patients was constant in Ramig 2001 and Robertson 1984. Johnson 1990 stated that drug therapy was constant for at least months prior to start of trial. It is important that drug therapy is kept constant for the duration of the trial as it has been shown that various drug therapies may affect speech quality (Biary 1988; Dann 1994; Stewart 1995).

DESCRIPTION OF PLACEBO

None of the included studies used a placebo treatment. 'No therapy' is an inadequate control for the speech therapy methods being studied as all the therapy groups were treated in an outpatients department of a hospital and therefore had to get up in time for their appointment, dress, travel, spend time in the company of other patients etc. None of this is speech and language therapy but it may have had an effect on the wellbeing and overall quality of life (Hawthorne effect) of the patients with Parkinson's disease who took part.

\section{DATA ANALYSIS}

The data were analysed on a per protocol basis in Robertson 1984 (see Glossary Table 1), this means that the analysis of the data could be biased if the drop-outs were due to the unacceptability of the placebo (as all of the drop-outs were in the placebo arm). There were four drop-outs in this study despite it only running for two weeks. No baseline information was given for these patients. It is assumed that Johnson 1990 and Ramig 2001 analysed their data on an intention-to-treat basis (see Glossary Table 1) as there were no withdrawals from these studies, though this was not stated in the publications.

None of the studies statistically compared the change in a given outcome measure (i.e. score after therapy minus score at baseline) between the two groups (i.e. change due to therapy versus change due to placebo). Robertson 1984 and Ramig 2001 statistically compared the final scores between the two therapy groups. This relies on the baseline characteristics of the two groups being very similar, but with such small numbers of participants, variations between the two groups at baseline are common. Johnson 1990 statistically compared the change in an outcome for each group individually over time. This means that this trial does not examine whether SLT is better than no treatment, only that changes, if any, occurred after a given therapy.

OUTCOME MEASURES

An analysis of the clinimetric soundness of the outcome measures used is included in the Discussion section of the review.

\section{Effects of interventions}

See Glossary: Table 1 and the Summary of Results Table: Table 3 A total of 63 individuals were randomised into the three trials included in this review, no analysable data were available for the 22 patients from Robertson 1984, this meant that the number available for numerical analysis was just 41. Both Ramig 2001 and Johnson 1990 compared mean values before and after the treatment. We converted these to mean changes from baseline and the mean differences between the groups were calculated along with $95 \%$ confidence intervals $(95 \% \mathrm{CI}$ ) and significance values (P).

\section{SUMMARY ASSESSMENTS OF SPEECH IMPAIRMENT}

Johnson 1990 measured total impairment with the Frenchay Dysarthria Assessment, which improved significantly with therapy by 29.0 points $(95 \%$ CI 13.7 to 44.3 ; $\mathrm{P}=0.0002)$ compared to the no therapy group.

Robertson 1984 stated that the scores of the Dysarthria Profile were comparable in the two groups at baseline. Immediately after therapy the scores were significantly higher in the treatment group compared to the placebo group (ANOVA: $\mathrm{F}(1,16)=3.85, \mathrm{P}<$ $0.05)$. 


\section{SPEECH IMPAIRMENTS: LOUDNESS}

See Glossary: Table 1 for explanations of the various terms used to describe loudness.

Ramig 2001 measured loudness objectively (sound pressure level, dB) with four different speaking modes, whilst Johnson 1990 studied two speaking modes (volume, dB). Both Ramig 2001 and Johnson 1990 measured the mean loudness of a monologue. In Ramig 2001 the patient chose the subject on which to talk, whilst in Johnson 1990 the patients were given a list of subjects to select from. There was a statistically significant improvement in objective loudness of $11.0 \mathrm{~dB}$ (95\% CI 3.98 to $18.02 ; \mathrm{P}=0.002)$ in Johnson 1990 and 5.4 dB (95\% CI 2.6 to 8.2; P = 0.0002) in Ramig 2001 immediately after therapy. The results from these studies are combined in a forest plot in Figure 3: although the treatment methods were not the same in these two trials the plot shows a significant improvement with therapy compared to no therapy of $6.17 \mathrm{~dB}(95 \%$ CI 3.57 to 8.77 ; P < 0.00001). Ramig 2001 continued to follow their groups for six months at which point the improvement in objective loudness had reduced to 3.5 $\mathrm{dB}(95 \%$ CI 0.9 to 6.1$)$, but this was still a significant increase
$(\mathrm{P}=0.009)$. When the patients were asked to describe a picture in Ramig 2001 the mean objective loudness of speech was also improved compared to baseline by $5.2 \mathrm{~dB}$ (95\% CI 2.0 to 8.4; $\mathrm{P}=0.001)$ more in the LSVT group than the no therapy group and this was maintained over six months $(4.2 \mathrm{~dB}, 95 \% \mathrm{CI} 1.1$ to 7.3; $\mathrm{P}=0.008)$. Ramig 2001 and Johnson 1990 both measured the mean objective loudness of reading a standard passage both of which improved by $6.3 \mathrm{~dB}(95 \% \mathrm{CI} 3.5$ to $9.1 ; \mathrm{P}=0.0007)$ and $11.0 \mathrm{~dB}$ (95\% CI 5.2 to $16.9 ; \mathrm{P}=0.0002)$, respectively. These results were also meta-analysed in a forest plot, shown in Figure 4, the combined therapies gave an increase of $7.18 \mathrm{~dB}$ (95\% CI 4.65 to $9.71 ; \mathrm{P}=0.00001$ ) when compared with no therapy. Ramig 2001 again recorded reading loudness six months after therapy and showed that this improvement was mostly maintained $(4.5 \mathrm{~dB}$, 95\% CI 1.9 to $7.1 ; \mathrm{P}=0.0007$ ). Ramig 2001 also measured the mean objective loudness of a prolonged 'ah'. Again this improved after therapy by $12.1 \mathrm{~dB}(95 \% \mathrm{CI} 8.9$ to $15.4 ; \mathrm{P}<0.00001)$ and the improvement was maintained for six months $(9.4 \mathrm{~dB}, 95 \% \mathrm{CI}$ 6.2 to $12.6 ; \mathrm{P}<0.00001)$.

Figure 3. Forest plot of comparison: I SLT Therapy versus no therapy, outcome: I.I SPL monologue pre/post.

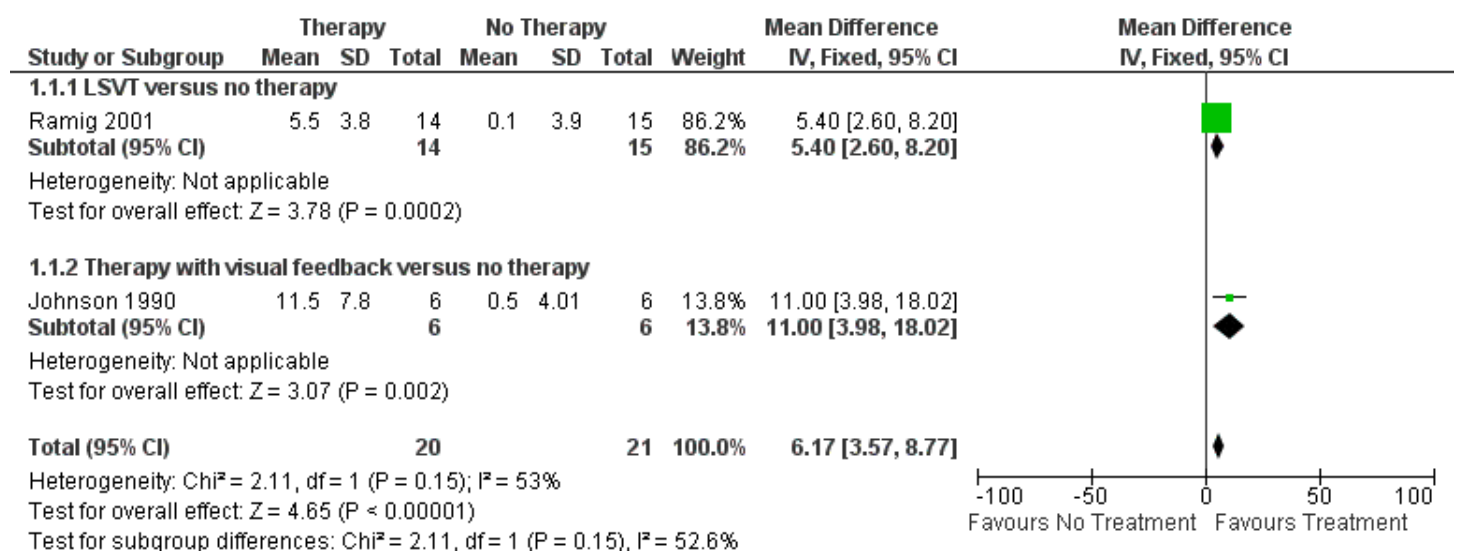


Figure 4. Forest plot of comparison: I SLT therapy versus no SLT therapy, outcome: I.2 SPL reading pre/post.

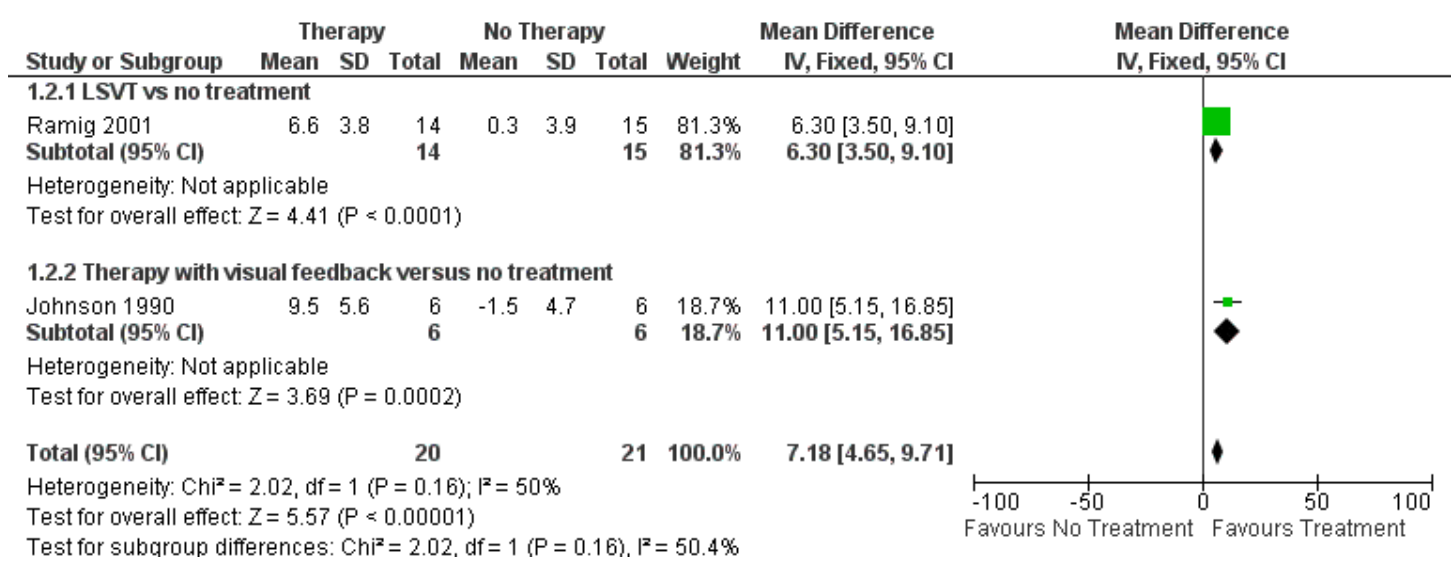

\section{SPEECH IMPAIRMENTS: MONOTONICITY}

Johnson 1990 measured two variables that could influence the monotonicity of speech and voice. Maximum pitch range was found by asking the patients to sing up and down to their highest and lowest notes. This improved by $66 \mathrm{~Hz}$ after therapy but the change was not significant $(95 \% \mathrm{CI}-4.4$ to $136.6 ; \mathrm{P}=0.07)$. Maximum volume range was measured by asking the patients to count to five starting with the quietest voice they could achieve and ending with the loudest. There was a significant improvement of $23.7 \mathrm{~dB}(95 \% \mathrm{CI} 9.3$ to $38.1 ; \mathrm{P}=0.001)$ after therapy for this outcome.

\section{SPEECH IMPAIRMENTS: PITCH}

Johnson 1990 measured the mean pitch (fundamental frequency, see Glossary Table 1) of saying 'ah'. There was a non-significant difference of $-65 \mathrm{~Hz}(95 \% \mathrm{CI}-133$ to 2; $\mathrm{P}=0.06$ ) between the two groups, with approximately $30 \mathrm{~Hz}$ of this change attributable to an increase in the placebo group.

\section{OTHER OUTCOMES}

No study provided any information on activities of daily living, intelligibility of speech, quality of life, adverse events, carer outcomes or performed an economic analysis.

\section{DISCUSSION}

\section{Summary of main results}

1. Three randomised controlled trials were found comparing speech and language therapy with placebo (63 participants); numerical data were only available in two of the trials (41 participants). These trials varied significantly in their methodology.
2. All of the trials claimed a positive effect of speech and language therapy on speech problems in Parkinson's disease. Many of the outcome measures examined appeared to improve by a clinically significant amount after therapy. However, considering the small number of patients with Parkinson's disease examined, the methodological flaws in the studies, and the possibility of publication bias, it is unsafe to draw firm conclusions regarding the efficacy of speech and language therapy.

3. Large well designed RCTs are needed to assess whether SLT is effective in treating speech problems in Parkinson's disease.

\section{Overall completeness and applicability of evidence}

\section{OUTCOME MEASURES}

The outcome measures varied greatly between the trials. In two of the three trials outcome measures were only assessed at baseline and immediately after therapy. It would have been valuable to know the long-term duration of any improvement following therapy. Summary assessments of speech impairment

The Frenchay Dysarthria assessment has been validated for use with Parkinson's disease patients. Personal communication with the author of the scale has revealed that it is hard to determine whether a 29 point gain in the summary score is clinically useful. If the improvement was in areas associated with improvements in 'speech' it would be seen as clinically useful, however, if gains were in other parts of the test then they might not have a significant impact on the patient's communicative ability.

Speech impairments: loudness

Parkinsonian speech is often characterised by a quiet voice. This can exacerbate problems with intelligibility as listeners strain to 
hear what is being said by the patient. The tests can be divided into spontaneous and prompted speech. Spontaneous speech, such as a monologue or describing a picture is harder for people with Parkinson's disease as it requires greater cognitive effort. However, it is more 'real life' than the prompted speech tests (reading or saying 'ah'). It can be suggested that with current computer technology it should be possible to record a conversation with a patient, remove the therapists' voice and then carry out vocal parameter analysis (volume, pitch etc.) on the patient's speech as it sounds in their most common speaking activity.

The objective loudness (volume or sound pressure level measured in decibels with a microphone) of the patients' speech improved, with all types of speech modality measured, after therapy. The size of these improvements had reduced a little after six months. When considering whether these improvements are clinically useful it is helpful to examine Ramig 2001's study. In addition to the therapy and placebo groups of Parkinson's disease patients, they also examined 14 healthy, age matched people with no speech or voice impairments. When the objective loudness of their speech is compared to the total Parkinson's disease group (therapy and placebo combined) at baseline, averaged over all four of the outcomes assessed, the healthy participants spoke $2.8 \mathrm{~dB}$ louder. All of the improvements immediately after therapy in the patients with Parkinson's disease are at least twice as large as this, and even at six months later all of the improvements in loudness are more than $3.5 \mathrm{~dB}$. Therefore, this suggests that these increases in the loudness of speech are useful to the participants. However, as the patients and their carers were not asked whether they felt that their speech had got louder and/or more intelligible, it cannot be said what impact these improvements had on the patient's communication abilities.

Speech impairments: monotonicity

It is accepted that a patient's maximum loudness and pitch variation will have an impact on the monotonicity of their day-to-day conversation. It would have been more useful to measure the objective loudness and pitch variability in a sample of speech, however, it is recognised that at the time of the Johnson 1990 study the technology may not have been easily available.

Speech impairments: pitch

The only measure of pitch of the patient's speech was measured by asking them to say 'ah'. This is a highly artificial situation, and the standard deviations were quite large which may explain why the pitch reduced in the therapy group, when therapy would have been aimed at increasing pitch.

Activities of daily living (ADL)

It is important to assess the impact that poor communication has on the ADL of patients with Parkinson's disease. For example, many patients have difficulty using a telephone or talking to strangers. If after therapy they found that these skills improved, this could also reduce their sense of isolation and so probably also increase their quality of life.

Adverse Events
Adverse events were not reported by any of the trials included in this review. Although the risk associated with speech and language therapy is low, patients could be affected by vocal strain or abuse during high effort exercises

Quality of life (QOL) and intelligibility

It is now generally accepted that quality of life measures should be used as the primary outcome of interest in larger clinical trials to provide a global patient-orientated perspective on an intervention. However, with speech and language therapy it could be argued that the primary outcome of interest is improved intelligibility. At present quantifying this multi-factorial outcome is difficult and there are few validated scoring systems that assess this outcome. One available system is the Assessment of Intelligibility for Dysarthric Speech (AIDS), which quantifies single-word intelligibility, sentence intelligibility, and speaking rate. None of the trials reviewed used QOL or intelligibility scales. Therefore, the trials reported here cannot be used to inform sample size calculations for future trials.

Depression

The effectiveness of the therapy could potentially be affected by depression. Depressed patients could be less compliant both during the therapy sessions and also in the practice at home. The therapy itself might affect depression. The patient's mood may improve due to the attention they are being paid by the therapist, by getting out of the house and meeting other people. A well designed placebo intervention would control for the non-therapeutic confounders. If the therapy affected the patient's physical well-being so that they felt more in control and able to carry out more of their ADL independently, this could improve the patient's mood. Also it is important to measure depression, as a number of surveys (GPDS 2000; Karlsen 1999; Visser 2008; Zach 2004) have found depression to be the main contributor to reduction in quality of life due to Parkinson's disease.

\section{Carer outcomes}

Approximately $75 \%$ of Parkinson's disease patients live with a partner, who is usually of a similar age and may have disabilities of their own (Lloyd 1999). The impact of caring for a person with Parkinson's can be severe (O'Reilly 1996), and it would be hoped that an intervention such as speech and language therapy could have a positive effect on the carer's life as well as the patient's. It is also important to assess the carer's perception of the speech impairment as they are usually the ones that have the greatest interaction with the person with Parkinson's disease.

Health economics

No health economics analysis of speech and language therapy has been performed, which precludes an understanding of the economic value of this therapy. If we can prove that SLT works, we then need to persuade health care purchasers to buy the service. They need to know whether it is cost neutral or whether it increases or decreases the overall costs of care and whether this is balanced by improvements in efficacy.

SPEECH AND LANGUAGE THERAPY METHODOLOGY 
There is no consensus amongst therapists on which SLT method to use or whether it should be a combination of methods. A recent survey of speech and language therapists in the UK (Miller 2011a) showed a high proportion of patients with Parkinson's disease referred for SLT receive only an assessment, advice and review service. When treatment methods were employed, voice quality was most commonly addressed with LSVT or other vocal loudness exercises and intelligibility was treated with pacing/rate control exercises supported by work on loudness. Psychosocial and language strategies were rarely employed by the therapists surveyed despite these being flagged as important reasons for referral. Over 75\% of all therapists surveyed wanted further training and over half of these specifically desired training in LSVT techniques. As part of the same study a survey of SLT provision was carried out with patients with Parkinson's disease and their carer's (Miller 2011b). Of the 83 patients who had received any treatment from a speech and language therapist, 56\% had their sessions in a local clinic or hospital outpatients setting and 37\% were visited in their own home. Median duration of therapy for those treated was four weeks with $68 \%$ attending a single weekly session, a further $22 \%$, who were predominantly receiving LSVT, had four or more therapy sessions per week. Most sessions (80\%) lasted between 30-60 minutes.

This Cochrane review highlights the fact that there is insufficient trial evidence to support any form of SLT for speech problems in Parkinson's disease. Lee Silverman Voice Therapy (LSVT; Ramig 2001) concentrates solely on volume with participants being encouraged to 'think loud'. Johnson 1990 and Robertson 1984 used a more traditional multi-dimensional approach, both using visual feedback. They used vocal drills to improve the patients' overall speech quality and their perception of their speech.

\section{SPEECH AND LANGUAGE THERAPY TERMINOLOGY}

The terminology in this review has been aimed at a general clinical audience unlike some of the trial reports. It is hoped that this will improve understanding by non-speech and language therapists. In an attempt to make reading the original reports easier we have included a glossary in this review (Table 1: Glossary).

The same outcome measure was often labelled differently in different trials (e.g. volume and sound pressure level), which adds further to the confusion. It was also difficult for a non-specialist to determine the value of any given change in the vocal characteristics measured in these trials. Care should be taken when writing reports of speech therapy outcomes that an association is made with the direction and size of change in a given measure and its impact on the communication ability of the patient. For example, pitch range (fundamental frequency variability) is important because Parkinsonian speech tends to drift towards a monotone with none of the pitch variations that are important in conveying the sense of a phrase.

\section{Quality of the evidence}

METHODOLOGICAL QUALITY
Methodological quality and standard of reporting was poor. However, two of the three studies were published before the CONSORT guidelines were published (1996).

The trials used insufficient numbers of participants to avoid reaching false negative conclusions and to reduce the possibility of selection bias. Only $29 \%$ of the patients enrolled into the trials were female. This is in contrast to the general population of Parkinson's disease patients where the prevalence of the disease is evenly divided across the sexes (Tanner 1996). This is a common finding in Parkinson's disease trials but raises questions as to whether the results can be generalized across the whole Parkinson's disease population and to women in particular.

The method of randomisation was not stated in Johnson 1990. Alternate allocation was used in Robertson 1984 and Ramig 2001 picked numbers out of a hat, both of which are fallible as these methods are not truly random and allocation is not concealed.

All three trials failed to clearly define their disease of interest or state their inclusion and exclusion criteria. It is vital that eligibility criteria are well defined so that it is understood what sort of a population were treated. For example, it is important that the Parkinson's disease accords with the UK Brain Bank Parkinson's Disease criteria (Gibb 1988). This will reduce the likelihood of including individuals with Parkinson's plus syndrome which have a significantly different clinical course compared to idiopathic Parkinson's disease. The eligibility criteria should also define the severity of Parkinson's disease and the speech problems in those eligible to participate, and state clearly any exclusion criteria such as dementia. This would allow an easier assessment of the applicability of the results in real clinical situations.

It is recognised that inclusion of credible placebo arms in rehabilitation therapy trials is more challenging and expensive than in drug trials. A control arm receiving 'no therapy' leaves both the therapist and the patient unblinded which could lead to performance bias. It is important, therefore, to include control groups which account for time and attention given to active therapy groups. People with Parkinson's disease are frequently socially isolated and the attention paid to them could have a significant impact upon their mood and perception of their disability. However, it is recognised that a 'placebo' therapy may be impractical to apply in large multicentre trials and that an untreated 'best medical practice' group would represent a less than adequate comparator. Although the estimate of the size of improvement due to therapy would be more difficult to determine because of the placebo effect, which is estimated at around 16\% in Parkinson's disease (Goetz 2008), this design may be more reflective of current therapy provision and practice.

\section{A U THORS, CONCLUSIONS}

\section{Implications for practice}

Improvements in speech impairments were noted in the 41 par- 
ticipants evaluable from these studies, though it cannot be stated whether or not these changes were of a clinically useful magnitude. Considering the methodological flaws in many of the studies, the small number of patients examined, and the possibility of publication bias, there is insufficient evidence to support or refute the efficacy of speech and language therapy for speech problems in Parkinson's disease.

\section{Implications for research}

- To obtain proof of the efficacy of speech and language therapy for speech disorders in Parkinson's disease patients large randomised placebo-controlled trials are required. A rigorous method of randomisation should be used and the allocation adequately concealed. Data should be analysed according to intention-to-treat principles. The trial should be reported according to the guidelines set out in the CONSORT statement (CONSORT 1996). This review emphasises many methodological shortcomings in the three trials of speech and language therapy versus placebo for speech problems in Parkinson's disease. The issues arising from this review have a significant bearing on the conduct of future speech and language therapy trials in Parkinson's disease and other conditions:-

- $\quad$ firm diagnostic criteria should be used (e.g. UK Parkinson's Disease Brain Bank Criteria) (Gibb 1988);

- inclusion and exclusion criteria should be clear and trials should aim to enrol uniform cohorts of Parkinson disease patients;

- $\quad$ investigators should clarify at what stage of the disease speech and language therapy is being evaluated;

- $\quad$ trials must have sufficient numbers of participants to avoid false positive or false negative conclusions;

- ideally trials should include an adequate placebo control groupalthough it is recognised that an untreated 'best medical practice' group may be more practicable;

- $\quad$ trials must include a very clear description of the therapeutic intervention;

- $\quad$ patients should be followed for at least six months after treatment to assess any long-term effects of the SLT intervention;

- for some scales, trials should report whether scores on impairment and disability refer to the 'on' or 'off' phase;

- $\quad$ suitable clinimetrically sound outcome measures should be chosen so that the efficacy and effectiveness of SLT can be assessed and an economic analysis performed. Outcomes which have meaning to Parkinson's disease patients and carers should be used wherever possible since they need to know the value of SLT in practical terms;

- the data must be analysed on an intention-to-treat basis and the change in an outcome measure must be compared statistically across the two therapy groups;

- $\quad$ associations between size/direction of changes in outcome measures and the ability of the patients to communicate should be made, with intelligibility used as a key outcome measure to facilitate this.

\section{ACKNOWLEDGEMENTS}

We would like to thank the authors of the included studies who assisted in providing unpublished data and clarification of their methods. Thanks also to the people contacted whilst locating unpublished trials. Thanks to Dr Richard Barham at the National Physics Laboratory for his assistance with the glossary, to Ashwini Sreekanta at the University of Birmingham for her work on the search strategy and to Maxwell Barnish at the University of East Anglia for his contribution to the search for studies.

\section{RE FER E NCES}

\section{References to studies included in this review}

Johnson 1990 \{published and unpublished data\}

* Johnson JA, Pring TR. Speech therapy and Parkinson's disease: A review and further data. British Journal of Disorders of Communication 1990;25:183-94.

Ramig 2001 \{published and unpublished data\}

Ramig LO, Sapir S, Fox C, Countryman S. Changes in vocal loudness following intensive voice treatment (LSVT (R)) in individuals with Parkinson's disease: A comparison with untreated patients and normal age-matched controls. Movement Disorders 2001;16(1):79-83.
Robertson 1984 \{published data only\}

* Robertson SJ, Thomson F. Speech therapy in Parkinson's

disease: a study of the efficacy and long term effects of intensive treatment. British Journal of Disorders of Communication 1984;19:213-24.

\section{References to studies excluded from this review}

\author{
Aguiar 2009 \{published data only\} \\ Aguiar B, Aljanati R, Martinovic M, Pomar V, Ojeda A, \\ Gonzalez N, et al.Parkinsonian dysarthria Uruguayan \\ experience in a multidisciplinary team (open trial). \\ Movement Disorders 2009;24(S1):S365.
}


Corte 2009 \{published data only\}

Corte B, Neto PL. Music therapy on Parkinson disease.

Ciencia \& Saude Coletiva 2009;14(6):2295-304.

Cotter 2003 \{published data only\}

Cotter D. A pilot study to investigate if frequency of therapy alters outcomes of the Lee Silverman Voice Treatment (LSVT) programme for patients with Parkinson's disease. National Research Register 2003.

Evans 2006 \{published data only\}

Evans C. Group singing for someone with Parkinson's disease. National Research Register 2006.

Katsikitis 1996 \{published data only\}

* Katsikitis M, Pilowsky I. A controlled study of facial mobility treatment in Parkinson's disease. Journal of Psychosomatic Research 1996;40(4):387-96.

Patti 1996 \{published data only\}

* Patti F, Reggio A, Nicoletti F, Sellaroli T, Deinite G, Nicoletti FR. Effects of rehabilitation therapy on parkinsonians' disability and functional independence. Journal of Neurologic Rehabilitation 1996;10(4):223-31.

Quedas 2007 \{published data only\}

Quedas A, Duprat AdC, Gasparini G. Lombard's effect's implication in intensity, fundamental frequency and stability on the voice of individuals with Parkinson's disease. Revista Brasileira de Otorrinolaringologia 2007;73(5):675-83.

Sapir 2007 \{published data only (unpublished sought but not used)\} Sapir S, Spielman JL, Ramig LO, Story BH, Fox C. Effects of intensive voice treatment (the Lee Silverman Voice Treatment [LSVT]) on vowel articulation in dysarthric individuals with idiopathic Parkinson disease: Acoustic and perceptual findings. Journal of Speech Language and Hearing Research 2007;50(4):899-912.

Scott 1984 \{published data only\}

Scott S, Caird FI. The response of the apparent receptive speech disorder of Parkinsons-disease to speech-therapy. Journal of Neurology Neurosurgery and Psychiatry 1984;47 (3):302-4.

Silverman 2006 \{published data only\}

Silverman EP, Sapienza CM, Saleem A, Carmichael C, Davenport PW, Hoffman-Ruddy B, et al.Tutorial on maximum inspiratory and expiratory mouth pressures in individuals with idiopathic Parkinson disease (IPD) and the preliminary results of an expiratory muscle strength training program. Neurorehabilitation 2006;21(1):71-9.

Wang 2008 \{published data only\}

Wang EQ. Treating festinating speech with altered auditory feedback in Parkinson's disease: a preliminary report. Journal of Medical Speech-Language Pathology 2008;16(4): $275-82$.

Wohlert 2004 \{published data only\}

Wohlert AB. Service delivery variables and outcomes of treatment for hypokinetic dysarthria in Parkinson disease. Journal of Medical Speech-Language Pathology 2004;12(4): 235-9.

\section{References to ongoing studies}

Huber 2011 \{published data only\}

Huber JE. Use of external cueing to treat hypophonia in Parkinson's disease. RePORT 2011.

\section{Additional references}

\section{Biary 1988}

Biary N, Pimental PA, Langenberg PW. A double-blind trial of clonazepam in the treatment of Parkinson's dysarthria. Neurology 1988;38:255-8.

\section{CONSORT 1996}

Begg C, Cho M, Eastwood S, Horton R, Moher D, Olkin $\mathrm{I}$, et al.Improving the quality of reporting of randomised controlled trials. The CONSORT statement. JAMA 1996; 276(8):637-9.

\section{Dann 1994}

Dann N, Saunders H, Hunter PC, Hughes AJ. The response of parkinsonian dysarthria to dopaminergic stimulation. Movement Disorders 1994;9(Supplement 1):83.

\section{Darley 1969}

Darley FL, Aronson AE, Brown JR. Motor Speech Disorders. Philadelphia: Saunders, 1969.

Fleiss 1993

Fleiss JL. The statistical basis of meta-analysis. Statistical Methods in Medical Research 1993;2(2):121-45.

\section{Gibb 1988}

Gibb WRG, Lees AJ. The relevance of the Lewy body to the pathogenesis of idiopathic Parkinson's disease. Journal of Neurology, Neurosurgery and Psychiatry 1988;51:745-52.

\section{Goetz 2008}

Goetz CG, Wuu J, McDermott MP, Adler CH, Fahn S, Freed CR, et al.Placebo response in Parkinson's disease: Comparisons among 11 trials covering medical and surgical interventions. Movement Disorders 2008;23(5):690-9.

\section{GPDS 2000}

The Global Parkinson's Disease Survey. An insight into quality of life with Parkinson's disease. The Parkinson's Disease Society of the United Kingdom 2000.

\section{Higgins 2011}

Higgins JPT, Green S. Cochrane handbook for systematic reviews of interventions. Version 5.1.0. The Cochrane Collaboration, 2011.

\section{Karlsen 1999}

Karlsen KH, Larsen JP, Tandeburg E, Maeland JG. Influence of clinical and demographic variables on quality of life in patients with Parkinson's disease. Journal of Neurology, Neurosurgery and Psychiatry 1999;66(4):431-5.

\section{Lloyd 1999}

Lloyd M. The new community care for people for people with Parkinson's disease and their carers. In: Percival R, Hobson P editor(s). Parkinson's Disease: Studies in Psychological and Social Care. London: BPS Books, 1999: 13-59. 


\section{Logemann 1978}

Logemann JA, Fisher HB, Boshes B, Blonsky ER. Frequency and co-occurence of vocal tract dysfunctions in the speech of a large sample of Parkinson patients. Journal of Speech and Hearing Disorders 1978;43:47-57. [MEDLINE: 78134090]

\section{Mawdsley 1971}

Mawdsley C, Gamsu CV. Periodicity of speech in Parkinson's disease. Nature 1971;231(5301):315-6. [MEDLINE: 71202389]

Miller 2011a

Miller N, Noble E, Jones D, Deane KHO, Gibb C. Survey of speech and language therapy provision for people with Parkinson's disease in the United Kingdom: patients' and carers' perspectives. International Journal of Language \& Communication Disorders 2011;46(2):179-88.

\section{Miller 2011b}

Miller N, Deane KHO, Jones D, Noble E, Gibb C. National survey of speech and language therapy provision for people with Parkinson's disease in the United Kingdom: therapists' practices. International Journal of Language \& Communication Disorders 2011;46(2):189-201.

\section{NCC-CC 2006}

The National Collaborating Centre for Chronic Conditions. Parkinson's disease: National clinical guideline for diagnosis and management in primary and secondary care. Royal College of Physicians, London. London: Royal College of Physicians, 2006.

\section{O'Reilly 1996}

O'Reilly F, Finnan F, Allwright S, Davey Smith G, BenShlomo Y. The effects of caring for a spouse with Parkinson's disease on social, psychological and physical well-being. British Journal of General Practice 1996;46:507-12.

Parkinson's disease society 2008

Parkinson's disease society. Life with Parkinson's today room for improvement. Parkinson's disease society, London 2008.

\section{Ramig 1995}

Ramig L, Pawlas A, Countryman S. The Lee Silverman Voice Treatment: A practical guide to treating the voice and speech disorders in Parkinson's Disease. Iowa City: National Centre for Voice and Speech: University of Iowa, 1995.

\section{Rosenbek 1985}

Rosenbek JC, LaPointe LL. The dysarthrias: Description, diagnosis and treatment. In: Johns DF editor(s). Clinical management of neurogenic communicative disorders. 2nd Edition. Boston: Little Brown and Co, 1985.

\section{Sapir 2001}

Sapir S, Pawlas AA, Ramig LO, Countryman S, O’Brien C, Hoehn MM, et al.Voice and speech abnormalities in Parkinson disease: Relation to severity of motor impairment, duration of disease, medication, depression, gender, and age. Journal of Medical Speech-Language Pathology 2001;9 (4):213-26.

\section{Stewart 1995}

Stewart C, Winfield L, Hunt A, Bressman SB, Fahn S, Blitzer A, Brin MF. Speech dysfunction in early Parkinson's disease. Movement Disorders 1995;10(5):562-5. [MEDLINE: 96064327]

\section{Streifler 1984}

Streifler M, Hofman S. Disorders of verbal expression in Parkinsonism. Advances in Neurology 1984;40:385-93. [MEDLINE: 84124643]

\section{Tanner 1996}

Tanner CM, Hubble JP, Chan P. Epidemiology and genetics of Parkinson's disease. In: Watts RL, Koller WC editor(s). Movement Disorders. Neurologic Principles and Practise. New York: McGraw Hill, 1996:137-60. [: ISBN: 0-07-035203-8]

Visser 2008

Visser M, van Rooden SM, Verbaan D, Marinus J, Stiggelbout AM, van Hilten JJ. A comprehensive model of health-related quality of life in Parkinson's disease. Journal of Neurology 2008;255(10):1580-7.

\section{Zach 2004}

Zach M, Friedman A, Slawek J, Derejko M. Quality of life in Polish patients with long-lasting Parkinson's disease. Movement Disorders 2004;19(6):667-72.

* Indicates the major publication for the study. 


\title{
CHARACTERISTICS OF STUDIES
}

\section{Characteristics of included studies [ordered by study ID]}

\author{
Johnson 1990
}

Methods

Parallel group design. Randomisation method not stated. Data assumed to be analysed on an intention-to-treat basis. Treated as outpatients for 10 hours over 4 weeks. Assessed at baseline and immediately after therapy. The assessor was blinded. British study

\begin{tabular}{l|l}
\hline Participants & $\begin{array}{l}6 \text { patients per arm of study. No drop-outs were stated. Patients mean age } 63.5 \text { (treatment), } \\
64.8 \text { (placebo); } 5 \text { males and } 1 \text { female per group, baseline Hoehn and Yahr and duration of } \\
\text { condition not stated. No inclusion or exclusion criteria stated }\end{array}$ \\
\hline Interventions & $\begin{array}{l}\text { Treatment group: Individual exercises varied to suit patient's needs, emphasis placed on } \\
\text { prosodic features of pitch and volume with visual feedback used } \\
\text { Placebo group: No treatment described. } \\
\text { Drug therapy was constant for at least } 2 \text { months prior to trial }\end{array}$ \\
\hline
\end{tabular}

\begin{tabular}{|c|c|c|}
\hline Outcomes & \multicolumn{2}{|l|}{$\begin{array}{l}\text { Frenchay Dysarthria Assessment } \\
\text { Loudest volume } \\
\text { Volume range } \\
\text { Volume (speech \& reading) } \\
\text { Fundamental frequency } \\
\text { Modal pitch (speech \& reading) }\end{array}$} \\
\hline Notes & & \\
\hline \multicolumn{3}{|l|}{ Risk of bias } \\
\hline Bias & Authors' judgement & Support for judgement \\
\hline Specified eligibility criteria & Unclear risk & Criteria not stated \\
\hline Randomisation method & Unclear risk & Randomisation method not stated \\
\hline Adequate concealment of allocation & Unclear risk & Randomisation method not stated \\
\hline Similar at baseline & Low risk & $\begin{array}{l}\text { Groups similar in mean age and male/female } \\
\text { ratio }\end{array}$ \\
\hline Withdrawals $>10 \%$ & Low risk & No withdrawals \\
\hline Missing values $>10 \%$ & Low risk & No missing data \\
\hline Cointerventions constant & Low risk & Stable drug regimen throughout trial period \\
\hline Credible placebo & Unclear risk & Effect of time and attention undetermined \\
\hline
\end{tabular}


Johnson 1990 (Continued)

\begin{tabular}{|c|c|c|}
\hline Blinded assessors & Unclear risk & $\begin{array}{l}\text { Assessors blinded for Frenchay Dysarthria as- } \\
\text { sessment but not for eight remaining measures }\end{array}$ \\
\hline
\end{tabular}

\section{Ramig 2001}

\begin{tabular}{|c|c|c|}
\hline Methods & \multicolumn{2}{|c|}{$\begin{array}{l}\text { Parallel group design. Randomised by number pulled out of a hat allocation. Data assumed to } \\
\text { be analysed on an intention-to-treat basis. Treated as outpatients for } 16 \text { hours over } 4 \text { weeks. } \\
\text { Assessed at baseline and immediately after therapy. Not stated whether assessors were blinded. } \\
\text { American study }\end{array}$} \\
\hline Participants & \multicolumn{2}{|c|}{$\begin{array}{l}14 \text { patients in treatment group, } 15 \text { in placebo. Number of drop-outs not stated. Patients mean } \\
\text { age } 67.9 \text { (treatment), } 71.2 \text { (placebo); male/female } 7 / 7 \text { (treatment), } 7 / 8 \text { (placebo); Hoehn and } \\
\text { Yahr } 3.1 \text { (treatment), } 2.2 \text { (placebo); duration of condition/years } 8.6 \text { (LSVT), } 7.8 \text { (placebo) } \\
\text {. Inclusion criteria: Have adequate hearing for daily communication. No exclusion criteria } \\
\text { stated }\end{array}$} \\
\hline Interventions & \multicolumn{2}{|c|}{$\begin{array}{l}\text { Treatment group: Individual LSVT which targets maximising phonatory efficiency. Placebo } \\
\text { group: Treatment not described. Drug therapy was kept constant }\end{array}$} \\
\hline Outcomes & \multicolumn{2}{|c|}{$\begin{array}{l}\text { Volume for: } \\
\text { sustained vowel 'ah' phonation, } \\
\text { reading the Rainbow Passage, } \\
\text { speaking freely on self chosen topic, } \\
\text { describing 'The Cookie Theft' picture. }\end{array}$} \\
\hline \multicolumn{3}{|l|}{ Notes } \\
\hline \multicolumn{3}{|l|}{ Risk of bias } \\
\hline Bias & Authors' judgement & Support for judgement \\
\hline Specified eligibility criteria & Unclear risk & Criteria not stated \\
\hline Randomisation method & High risk & $\begin{array}{l}\text { Randomised by number pulled out of a hat } \\
\text { allocation }\end{array}$ \\
\hline Adequate concealment of allocation & High risk & $\begin{array}{l}\text { Randomised by number pulled out of a hat } \\
\text { allocation }\end{array}$ \\
\hline Similar at baseline & Low risk & $\begin{array}{l}\text { Groups similar in mean age, male/female ra- } \\
\text { tio, Hoehn \& Yahr and duration of condition }\end{array}$ \\
\hline Withdrawals $>10 \%$ & Low risk & No withdrawals \\
\hline Missing values $>10 \%$ & Low risk & No missing values \\
\hline Cointerventions constant & Low risk & Stable drug regimen throughout trial period \\
\hline
\end{tabular}


Ramig 2001 (Continued)

\begin{tabular}{lll}
\hline Credible placebo & Unclear risk & Effect of time and attention undetermined \\
\hline Blinded assessors & Unclear risk & Not stated whether assessors were blinded \\
\hline
\end{tabular}

Robertson 1984

Methods

Parallel group design. Randomised by alternate allocation. Data analysed on a per protocol basis. Treated as outpatients for 35-40 hours over 2 weeks. Assessed at baseline, immediately after therapy and 3 month later. Assessors were not blinded. British study

Participants

12 patients in treatment group, 10 in placebo. 4 drop-outs in placebo group. Patients mean age 58.4 (treatment), 68.1 (placebo); male/female 12/0 (treatment), 5/1 (placebo) - the sex and age of the drop-outs was not stated. The baseline duration of condition and Hoehn and Yahr score was not given. Inclusion criteria: Diagnosis of Parkinson's disease and on well stabilised drug regime. No exclusion criteria stated

Interventions

Treatment group: Group therapy supplemented with individual therapy if needed. Therapy aimed to improve respiration, voice production, pitch variation, loudness and intelligibility with video used for feedback. Placebo group: Assessed at same time intervals but no treatment. Drug therapy was constant

Outcomes Dysarthria profile.

Notes No raw data available.

Risk of bias

\begin{tabular}{lll}
\hline Bias & Authors' judgement & Support for judgement \\
\hline Specified eligibility criteria & Low risk & Inclusion criteria stated \\
\hline Randomisation method & High risk & Randomised by alternate allocation \\
\hline Adequate concealment of allocation & High risk & Randomised by alternate allocation \\
\hline Similar at baseline & Unclear risk & Baseline characteristics for drop-outs not pro- \\
\hline Withdrawals $>10 \%$ & High risk & vided drop outs from 22 recruited to trial \\
\hline Missing values $>10 \%$ & High risk & Baseline data for 4 drop outs not provided \\
\hline Cointerventions constant & Low risk & Stable drug regimen throughout trial period \\
\hline Credible placebo & Unclear risk & Effect of time and attention undetermined
\end{tabular}


Robertson 1984 (Continued)

\begin{tabular}{|c|c|c|}
\hline Blinded assessors & High risk & $\begin{array}{l}\text { All patients in the treatment group were as- } \\
\text { sessed and re-assessed by therapists not in- } \\
\text { volved in the therapy, while those in the con- } \\
\text { trol group were assessed by the co-authors }\end{array}$ \\
\hline
\end{tabular}

\section{Characteristics of excluded studies [ordered by study ID]}

\begin{tabular}{|c|c|}
\hline Study & Reason for exclusion \\
\hline Aguiar 2009 & $\begin{array}{l}\text { Controlled clinical trial compared the effect of a multidisciplinary program, dedicated to non-pharmacological } \\
\text { treatment, with no treatment. No data were available from SLT component }\end{array}$ \\
\hline Corte 2009 & $\begin{array}{l}\text { Trial reported in Portuguese, was carried out with a focus group and is not an RCT, discussions took place about } \\
\text { the importance of alternative practices like playing an instrument on patients with Parkinson's disease }\end{array}$ \\
\hline Cotter 2003 & $\begin{array}{l}\text { Three armed RCT with two groups receiving different schedules of LSVT and one group receiving no SLT. Trial } \\
\text { registration states the trial was due to run from } 2003 \text { to } 2005 \text {, no data or further information were available and } \\
\text { it could not be confirmed that the trial took place }\end{array}$ \\
\hline Evans 2006 & $\begin{array}{l}\text { Trial of group singing as a form of speech therapy for people with Parkinson's disease as a method of improving } \\
\text { and maintaining voice dynamics. This study did not include a control arm and hence was not randomised }\end{array}$ \\
\hline Katsikitis 1996 & $\begin{array}{l}\text { RCT examined the effect of orofacial physiotherapy on facial mobility. Although some of the outcome measures } \\
\text { such as 'distance of mouth opening' are important to intelligible speech, none of the outcome measures quantified } \\
\text { its affect on speech problems. As the aim of the trial was physical this was assessed in the 'Physiotherapy for patients } \\
\text { with Parkinson's disease' Cochrane review }\end{array}$ \\
\hline Patti 1996 & $\begin{array}{l}\text { RCT examined the effect of a program of inpatient rehabilitative therapy that included speech and language therapy } \\
\text { if the patient needed it. It was not clear how many of the patients in the study received speech and language } \\
\text { therapy. Also, all of the outcome measures were physiotherapeutic in nature and so this trial was assessed in the } \\
\text { 'Physiotherapy for patients with Parkinson's disease' Cochrane review }\end{array}$ \\
\hline Quedas 2007 & $\begin{array}{l}\text { Controlled trial based on Lombard's effect which states that a masking noise will produce a consistent increase in } \\
\text { voice intensity for most normal individuals. People with Parkinson's disease were evaluated before and after white } \\
\text { masking noise to test for improvement in intensity. The control group in this study consisted of healthy controls } \\
\text { and so the trial was not an RCT }\end{array}$ \\
\hline
\end{tabular}

Sapir 2007 Publication describes a sub-group of patients used in the Ramig 2001 study included in this review, however, additional patients were also randomised for analysis of the vowel articulation outcomes reported in this paper. The data cannot therefore be analysed as part of the Ramig 2001 trial nor can this be considered a separate trial due to the overlap of a portion of the patients

Scott 1984 Prosodic abnormality was assessed in adults with Parkinson's disease before and after a course of intensive domiciliary prosodic therapy. The control measurements were taken from the same patients over a two week period prior to the start of therapy so no randomisation of patients was necessary 
(Continued)

Silverman 2006 A sub-group of 3 patients in a trial examining the maximum inspiratory and expiratory mouth pressures of Parkinson's disease patients were given expiratory muscle strength training. No control group was used in the evaluation of this therapy

Wang 2008 Trial evaluated the use of altered auditory feedback to improve intelligibility of speech in patients with Parkinson's disease. Treatment pathways were randomised with patients taking part in 5 different testing conditions. No split data available

Wohlert 2004 Treatment schedules for delivery of LSVT were evaluated to determine the most effective frequency and duration of sessions. Not all patients who took part in this trial were randomised

\section{Characteristics of ongoing studies [ordered by study ID]}

Huber 2011

\begin{tabular}{|c|c|}
\hline Trial name or title & Use of External Cueing to treat hypophonia in Parkinson's disease \\
\hline Methods & Assessments made immediately after treatment and 6 months after treatment \\
\hline Participants & Individuals with Parkinson's disease. \\
\hline Interventions & $\begin{array}{l}\text { Treatment group: } 8 \text { week training plan with voice-activated appliance which creates babble noise in response } \\
\text { to speech, exploiting Lombard's effect (background noise naturally and automatically causes louder speech). } \\
\text { Placebo group: Unknown }\end{array}$ \\
\hline Outcomes & $\begin{array}{l}\text { Vocal intensity } \\
\text { Speech intelligibility } \\
\text { Clarity } \\
\text { Communicative competence } \\
\text { Respiratory strength } \\
\text { Respiratory kinematics during speech } \\
\text { Laryngeal aerodynamics } \\
\text { Articulatory acoustics }\end{array}$ \\
\hline Starting date & $01 / 04 / 2011$ \\
\hline Contact information & jhuber@purdue.edu \\
\hline Notes & American study. Trial registration information. Contacted author for further information but was unsuccessful \\
\hline
\end{tabular}


DATA AND ANALYSES

Comparison 1. SLT therapy versus no SLT therapy

\begin{tabular}{|c|c|c|c|c|}
\hline Outcome or subgroup title & $\begin{array}{l}\text { No. of } \\
\text { studies }\end{array}$ & $\begin{array}{c}\text { No. of } \\
\text { participants }\end{array}$ & Statistical method & Effect size \\
\hline 1 SPL monologue pre/post & 2 & 41 & Mean Difference (IV, Fixed, 95\% CI) & $6.17[3.57,8.77]$ \\
\hline 1.1 LSVT versus no therapy & 1 & 29 & Mean Difference (IV, Fixed, 95\% CI) & $5.40[2.60,8.20]$ \\
\hline $\begin{array}{l}\text { 1.2 Therapy with visual } \\
\text { feedback versus no therapy }\end{array}$ & 1 & 12 & Mean Difference (IV, Fixed, 95\% CI) & $11.0[3.98,18.02]$ \\
\hline $2 S P L$ reading pre/post & 2 & 41 & Mean Difference (IV, Fixed, 95\% CI) & $7.18[4.65,9.71]$ \\
\hline 2.1 LSVT vs no treatment & 1 & 29 & Mean Difference (IV, Fixed, 95\% CI) & $6.3[3.50,9.10]$ \\
\hline $\begin{array}{l}2.2 \text { Therapy with visual } \\
\text { feedback versus no treatment }\end{array}$ & 1 & 12 & Mean Difference (IV, Fixed, 95\% CI) & $11.0[5.15,16.85]$ \\
\hline $\begin{array}{l}3 \text { SPL monologue pre/6 month } \\
\text { follow-up }\end{array}$ & 1 & 29 & Mean Difference (IV, Fixed, 95\% CI) & $3.5[0.88,6.12]$ \\
\hline $\begin{array}{l}4 \text { SPL reading pre/6 month } \\
\text { follow-up }\end{array}$ & 1 & 29 & Mean Difference (IV, Fixed, 95\% CI) & $4.5[1.91,7.09]$ \\
\hline $\begin{array}{l}5 \text { SPL sustained phonation } \\
\text { pre/post }\end{array}$ & 1 & 29 & Mean Difference (IV, Fixed, 95\% CI) & $12.10[8.85,15.35]$ \\
\hline $\begin{array}{l}6 \text { SPL sustained phonation pre/6 } \\
\text { month follow-up }\end{array}$ & 1 & 29 & Mean Difference (IV, Fixed, 95\% CI) & $9.40[6.24,12.56]$ \\
\hline 7 SPL describing picture pre/post & 1 & 29 & Mean Difference (IV, Fixed, 95\% CI) & $5.2[2.02,8.38]$ \\
\hline $\begin{array}{l}8 \text { SPL describing picture pre/6 } \\
\text { month follow-up }\end{array}$ & 1 & 29 & Mean Difference (IV, Fixed, 95\% CI) & $4.2[1.11,7.29]$ \\
\hline $9 \mathrm{SPL} / \mathrm{i} /$ & 1 & 29 & Mean Difference (IV, Fixed, 95\% CI) & $8.4[5.15,11.65]$ \\
\hline $10 \mathrm{SPL} / \mathrm{u} /$ & 1 & 29 & Mean Difference (IV, Fixed, 95\% CI) & $5.2[1.83,8.57]$ \\
\hline $11 \mathrm{SPL} / \mathrm{a} /$ & 1 & 29 & Mean Difference (IV, Fixed, 95\% CI) & $7.5[3.53,11.47]$ \\
\hline $12 \mathrm{~F} 2 \mathrm{u}$ & 1 & 29 & Mean Difference (IV, Fixed, 95\% CI) & $\begin{array}{l}-96.0[-233.51,41 . \\
51]\end{array}$ \\
\hline $13 \mathrm{~F} 2 \mathrm{i} / \mathrm{F} 2 \mathrm{u}$ & 1 & 29 & Mean Difference (IV, Fixed, 95\% CI) & $0.18[-0.02,0.38]$ \\
\hline 14 Vowel goodness /i/ & 1 & 29 & Mean Difference (IV, Fixed, 95\% CI) & $15.20[7.12,23.28]$ \\
\hline 15 Vowel goodness /u/ & 1 & 29 & Mean Difference (IV, Fixed, 95\% CI) & $12.20[5.34,19.06]$ \\
\hline 16 Vowel goodness /a/ & 1 & 29 & Mean Difference (IV, Fixed, 95\% CI) & $7.4[-0.19,14.99]$ \\
\hline
\end{tabular}

Comparison 2. Therapy with visual feedback versus no treatment

\begin{tabular}{lccll} 
Outcome or subgroup title & $\begin{array}{c}\text { No. of } \\
\text { studies }\end{array}$ & $\begin{array}{c}\text { No. of } \\
\text { participants }\end{array}$ & Statistical method & Effect size \\
\hline 1 SPL monologue pre/post & 1 & 12 & Mean Difference (IV, Fixed, 95\% CI) & $11.0[3.98,18.02]$ \\
2 SPL reading pre/post & 1 & 12 & Mean Difference (IV, Fixed, 95\% CI) & $11.0[5.15,16.85]$ \\
3 Frenchay dysarthria assessment & 1 & 12 & Mean Difference (IV, Fixed, 95\% CI) & $29.0[13.66,44.34]$ \\
4 Pitch range pre/post & 1 & 12 & Mean Difference (IV, Fixed, 95\% CI) & $66.1[-4.44,136.64]$ \\
5 Volume range pre/post & 1 & 12 & Mean Difference (IV, Fixed, 95\% CI) & $23.7[9.30,38.10]$ \\
\hline
\end{tabular}

Speech and language therapy versus placebo or no intervention for speech problems in Parkinson's disease (Review) 


\section{Analysis I.I. Comparison I SLT therapy versus no SLT therapy, Outcome I SPL monologue pre/post.}

Review: Speech and language therapy versus placebo or no intervention for speech problems in Parkinson's disease

Comparison: I SLT therapy versus no SLT therapy

Outcome: I SPL monologue pre/post

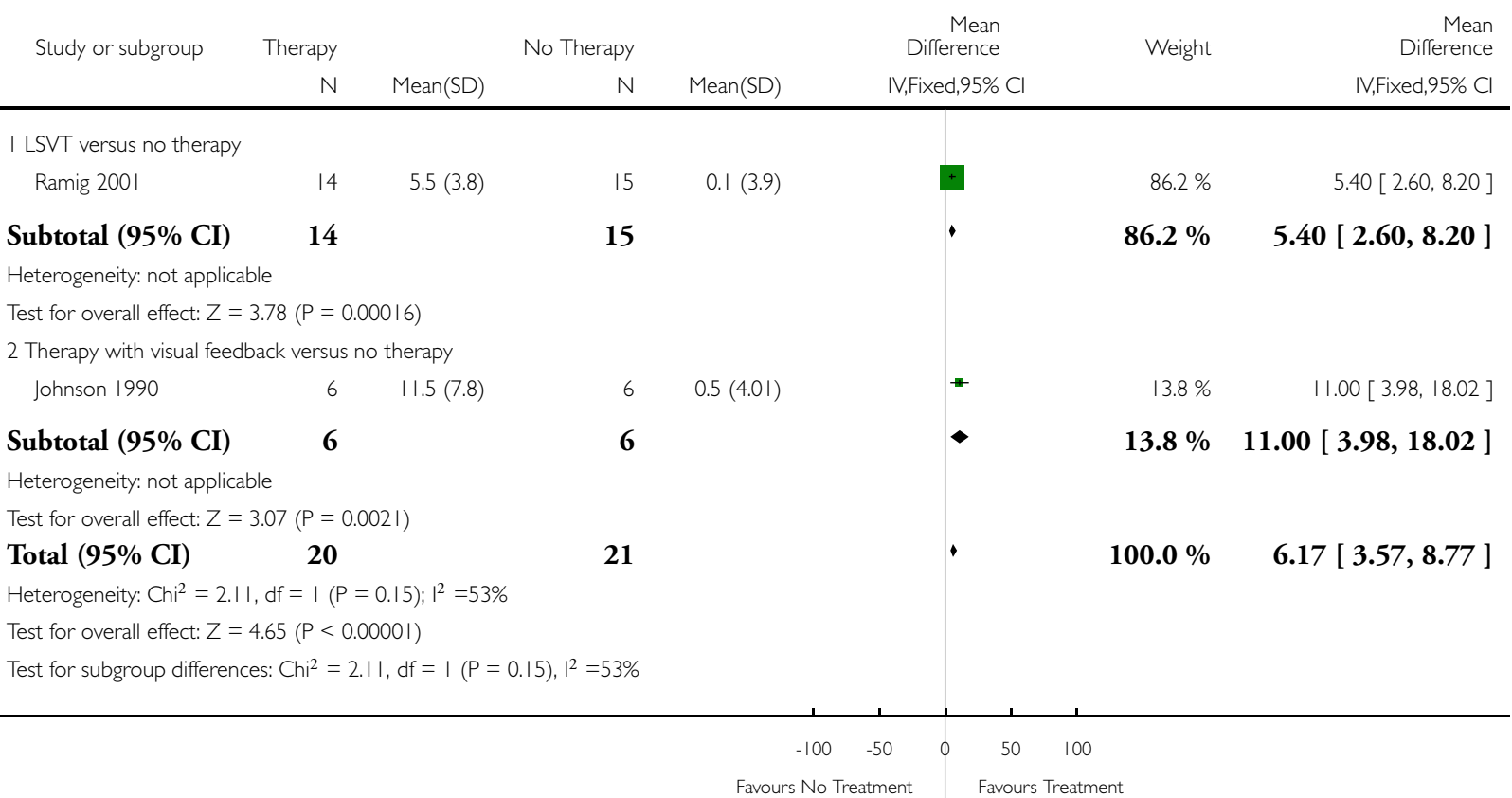




\section{Analysis I.2. Comparison I SLT therapy versus no SLT therapy, Outcome 2 SPL reading pre/post.}

Review: Speech and language therapy versus placebo or no intervention for speech problems in Parkinson's disease

Comparison: I SLT therapy versus no SLT therapy

Outcome: $2 \mathrm{SPL}$ reading pre/post

\begin{tabular}{|c|c|c|c|c|c|c|c|c|}
\hline \multirow[t]{2}{*}{ Study or subgroup } & \multirow{2}{*}{$\begin{array}{r}\text { Therapy } \\
\mathrm{N}\end{array}$} & & rapy & \multirow{2}{*}{\multicolumn{3}{|c|}{$\begin{array}{c}\text { Mean } \\
\text { Difference } \\
\text { IV,Fixed,95\% Cl }\end{array}$}} & \multirow[t]{2}{*}{ Weight } & \multirow{2}{*}{$\begin{array}{r}\text { Mean } \\
\text { Difference } \\
\text { IV,Fixed,95\% Cl }\end{array}$} \\
\hline & & Mean(SD) & $N$ & & & & & \\
\hline \multicolumn{9}{|l|}{ I LSVT vs no treatment } \\
\hline Ramig 2001 & 14 & $6.6(3.8)$ & 15 & $0.3(3.9)$ & & + & $81.3 \%$ & $6.30[3.50,9.10]$ \\
\hline Subtotal (95\% CI) & 14 & & 15 & & & - & $81.3 \%$ & $6.30[3.50,9.10]$ \\
\hline \multicolumn{9}{|c|}{ Heterogeneity: not applicable } \\
\hline \multicolumn{9}{|c|}{ Test for overall effect: $Z=4.4 \mathrm{I}(P=0.0000 \mathrm{I} \mathrm{I})$} \\
\hline \multicolumn{9}{|c|}{2 Therapy with visual feedback versus no treatment } \\
\hline Johnson 1990 & 6 & $9.5(5.6)$ & 6 & $-1.5(4.7)$ & & \# & $18.7 \%$ & $11.00[5.15,16.85]$ \\
\hline Subtotal $(95 \% \mathrm{CI})$ & 6 & & 6 & & & $\bullet$ & $18.7 \%$ & $11.00[5.15,16.85]$ \\
\hline \multicolumn{9}{|c|}{ Heterogeneity: not applicable } \\
\hline \multicolumn{9}{|c|}{ Test for overall effect: $Z=3.69(P=0.00023)$} \\
\hline Total $(95 \%$ CI $)$ & 20 & & 21 & & & - & $100.0 \%$ & $7.18[4.65,9.71]$ \\
\hline \multicolumn{9}{|c|}{ Heterogeneity: $\mathrm{Chi}^{2}=2.02, \mathrm{df}=\mathrm{I}(\mathrm{P}=0.16) ; \mathrm{I}^{2}=50 \%$} \\
\hline \multicolumn{9}{|c|}{ Test for overall effect: $Z=5.57(P<0.0000$ I) } \\
\hline \multicolumn{9}{|c|}{ Test for subgroup differences: $\mathrm{Chi}^{2}=2.02, \mathrm{df}=\mathrm{I}(\mathrm{P}=0.16), \mathrm{I}^{2}=50 \%$} \\
\hline & & & & -100 & -50 & 50 & 100 & \\
\hline
\end{tabular}


Analysis I.3. Comparison I SLT therapy versus no SLT therapy, Outcome 3 SPL monologue pre/6 month follow-up.

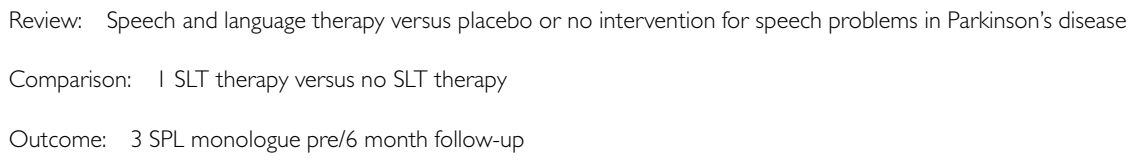

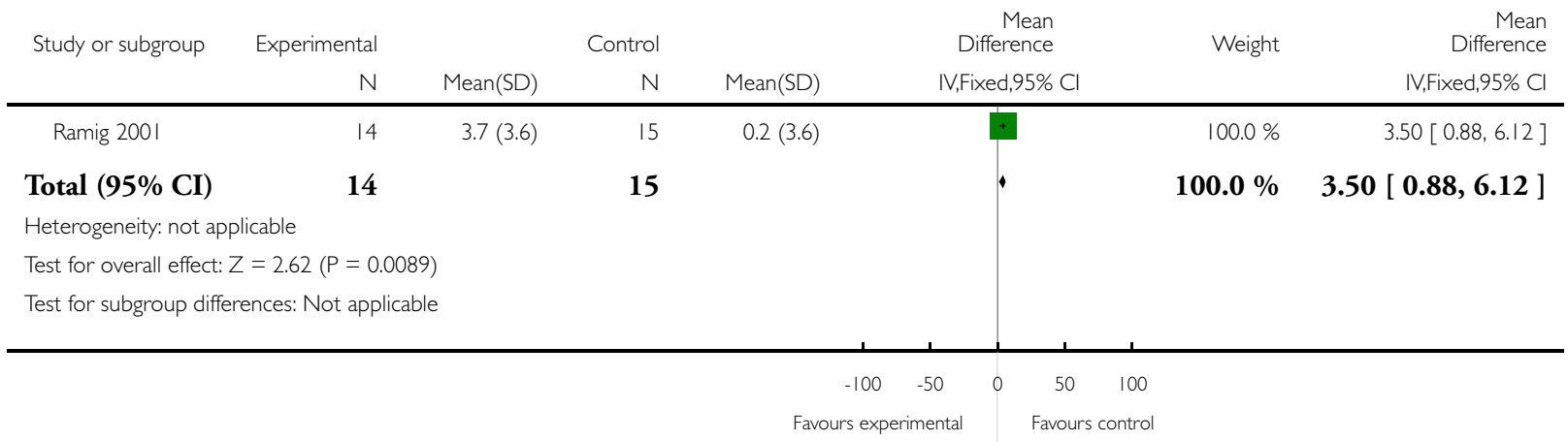

\section{Analysis I.4. Comparison I SLT therapy versus no SLT therapy, Outcome 4 SPL reading pre/6 month} follow-up.

Review: Speech and language therapy versus placebo or no intervention for speech problems in Parkinson's disease

Comparison: I SLT therapy versus no SLT therapy

Outcome: 4 SPL reading pre/6 month follow-up

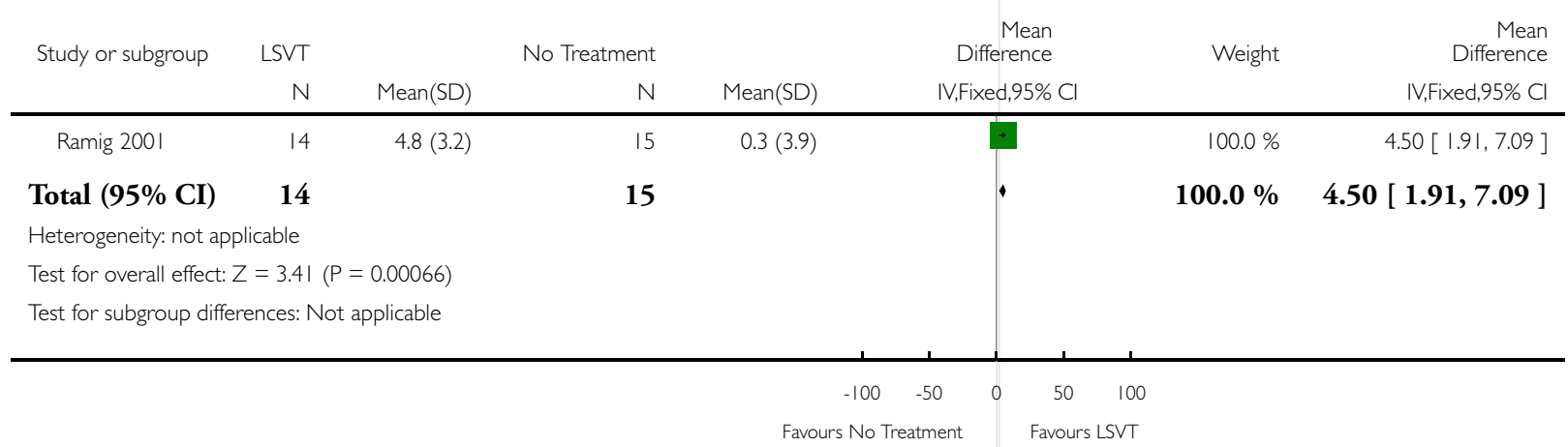


Analysis I.5. Comparison I SLT therapy versus no SLT therapy, Outcome 5 SPL sustained phonation pre/post.

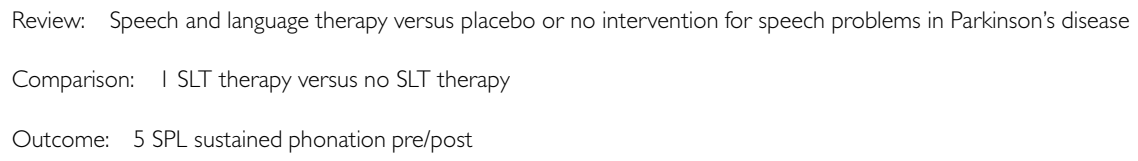

\begin{tabular}{|c|c|c|c|c|c|c|c|}
\hline \multirow[t]{2}{*}{ Study or subgroup } & \multirow{2}{*}{$\begin{array}{r}\text { LSVT } \\
N\end{array}$} & \multicolumn{3}{|c|}{ Placebo } & \multirow{2}{*}{$\begin{array}{c}\text { Mean } \\
\text { Difference } \\
\text { IV,Fixed,95\% Cl }\end{array}$} & \multirow[t]{2}{*}{ Weight } & \multirow{2}{*}{$\begin{array}{r}\text { Mean } \\
\text { Difference } \\
\text { IV,Fixed,95\% Cl }\end{array}$} \\
\hline & & Mean(SD) & $\mathrm{N}$ & Mean(SD) & & & \\
\hline Ramig 200I & 14 & I3.3(4.6) & 15 & $1.2(4.3)$ & + & $100.0 \%$ & $12.10[8.85,15.35]$ \\
\hline Total (95\% CI) & 14 & & 15 & & $\bullet$ & $100.0 \%$ & $12.10[8.85,15.35]$ \\
\hline \multicolumn{8}{|c|}{ Heterogeneity: not applicable } \\
\hline \multicolumn{8}{|c|}{ Test for overall effect: $Z=7.30(P<0.0000 I)$} \\
\hline \multicolumn{8}{|c|}{ Test for subgroup differences: Not applicable } \\
\hline
\end{tabular}

\section{Analysis I.6. Comparison I SLT therapy versus no SLT therapy, Outcome 6 SPL sustained phonation pre/6} month follow-up.

Review: Speech and language therapy versus placebo or no intervention for speech problems in Parkinson's disease

Comparison: I SLT therapy versus no SLT therapy

Outcome: $6 \mathrm{SPL}$ sustained phonation pre/6 month follow-up

\begin{tabular}{|c|c|c|c|c|c|c|c|c|c|}
\hline \multirow[t]{2}{*}{ Study or subgroup } & LSVT & \multicolumn{2}{|c|}{ No Treatment } & \multicolumn{4}{|c|}{$\begin{array}{r}\text { Mean } \\
\text { Difference }\end{array}$} & \multicolumn{2}{|r|}{$\begin{array}{r}\text { Mean } \\
\text { Difference }\end{array}$} \\
\hline & $\mathrm{N}$ & Mean(SD) & $\mathrm{N}$ & Mean(SD) & & & $\mathrm{ed}, 95 \% \mathrm{Cl}$ & & IV,Fixed,95\% Cl \\
\hline Ramig 200I & 14 & I $0.7(4.56)$ & 15 & $1.3(4.1)$ & & & & $100.0 \%$ & $9.40[6.24,12.56]$ \\
\hline Total $(95 \% \mathrm{CI})$ & 14 & & 15 & & & & - & $100.0 \%$ & $9.40[6.24,12.56]$ \\
\hline \multicolumn{10}{|c|}{ Heterogeneity: not applicable } \\
\hline \multicolumn{10}{|c|}{ Test for overall effect: $Z=5.82(P<0.0000 I)$} \\
\hline \multicolumn{10}{|c|}{ Test for subgroup differences: Not applicable } \\
\hline & & & & & -100 & -50 & 50 & 100 & \\
\hline
\end{tabular}




\section{Analysis I.7. Comparison I SLT therapy versus no SLT therapy, Outcome 7 SPL describing picture pre/post.}

Review: Speech and language therapy versus placebo or no intervention for speech problems in Parkinson's disease

Comparison: I SLT therapy versus no SLT therapy

Outcome: 7 SPL describing picture pre/post

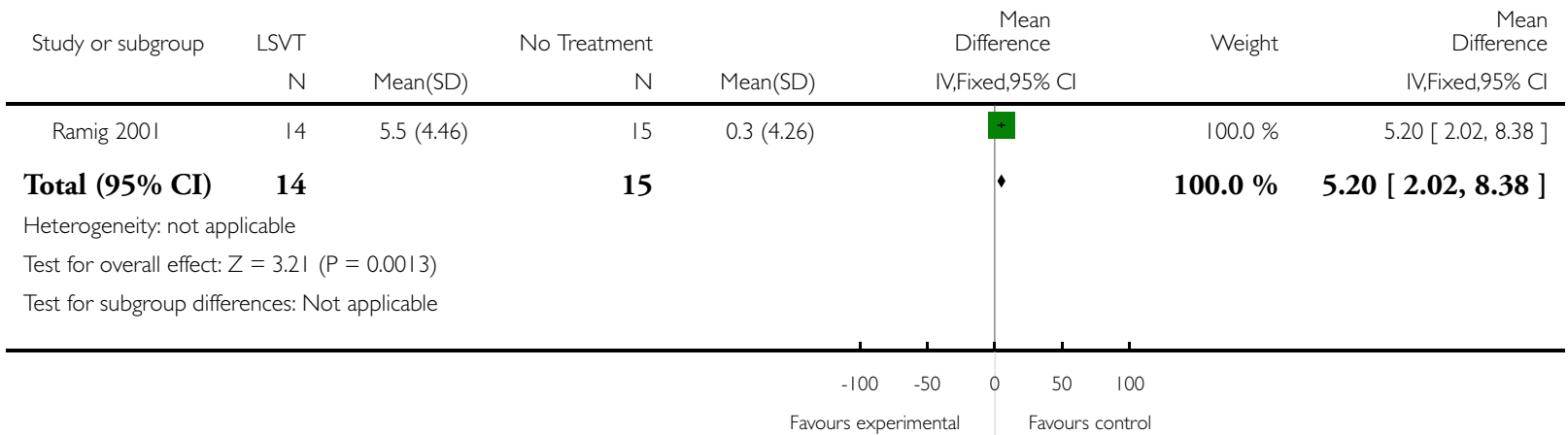

Analysis I.8. Comparison I SLT therapy versus no SLT therapy, Outcome 8 SPL describing picture pre/6 month follow-up.

Review: Speech and language therapy versus placebo or no intervention for speech problems in Parkinson's disease

Comparison: I SLT therapy versus no SLT therapy

Outcome: 8 SPL describing picture pre/6 month follow-up

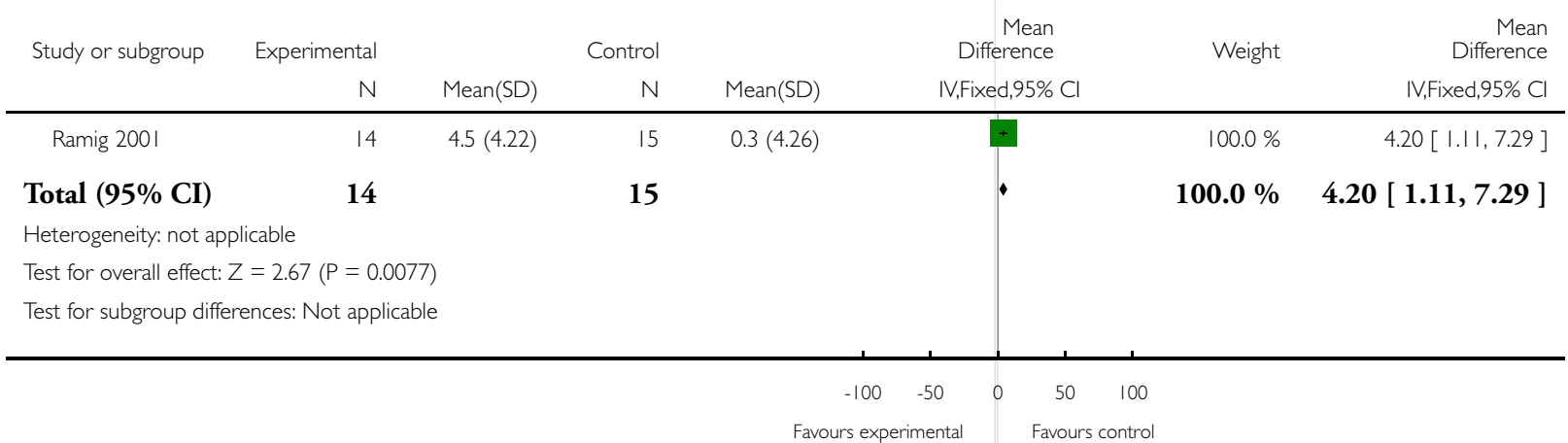




\section{Analysis I.9. Comparison I SLT therapy versus no SLT therapy, Outcome 9 SPL li/.}

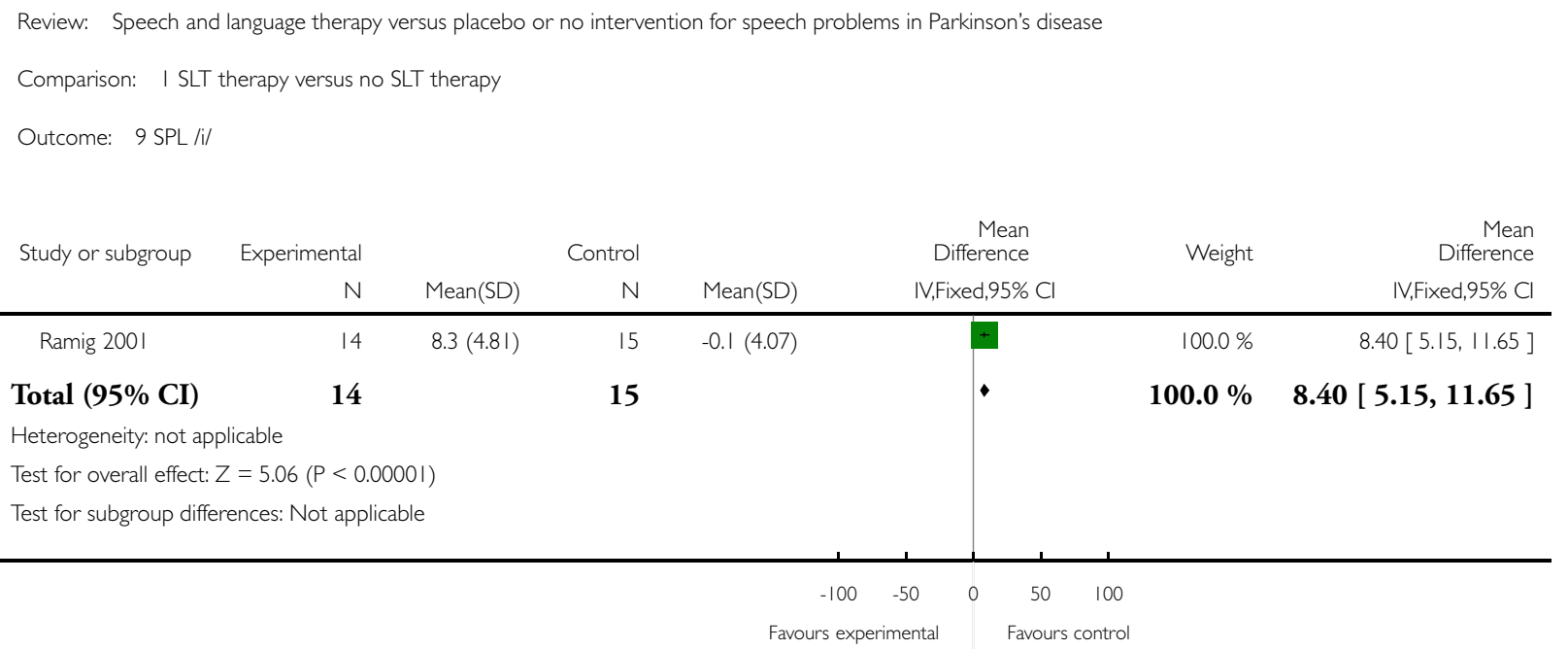

\section{Analysis I.I0. Comparison I SLT therapy versus no SLT therapy, Outcome 10 SPL /u/.}

Review: Speech and language therapy versus placebo or no intervention for speech problems in Parkinson's disease

Comparison: I SLT therapy versus no SLT therapy

Outcome: $10 \mathrm{SPL} / \mathrm{u} /$

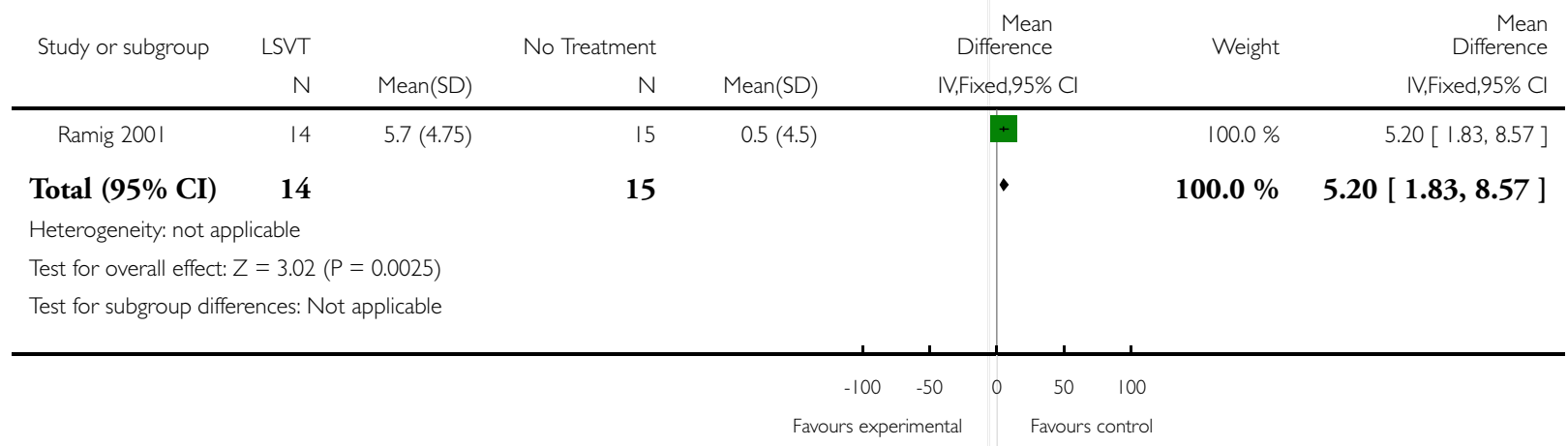




\section{Analysis I.I I. Comparison I SLT therapy versus no SLT therapy, Outcome II SPL /a/.}

\begin{tabular}{|c|c|c|c|c|c|c|c|}
\hline \multicolumn{8}{|c|}{ Comparison: I SLT therapy versus no SLT therapy } \\
\hline Outcome: || SPL & & & & & \multirow{3}{*}{$\begin{array}{c}\text { Mean } \\
\text { Difference } \\
\text { IV,Fixed,95\% Cl }\end{array}$} & & \\
\hline \multirow[t]{2}{*}{ Study or subgroup } & \multirow{2}{*}{$\begin{array}{r}\text { LSVT } \\
\mathrm{N}\end{array}$} & \multicolumn{3}{|c|}{ No Treatment } & & \multirow[t]{2}{*}{ Weight } & \multirow{2}{*}{$\begin{array}{r}\text { Mean } \\
\text { Difference } \\
\text { IV.Fixed,95\% C }\end{array}$} \\
\hline & & Mean(SD) & N & Mean(SD) & & & \\
\hline Ramig 200I & 14 & $8.5(5.66)$ & 15 & । (5.22) & + & $100.0 \%$ & $7.50[3.53,11.47]$ \\
\hline Total $(95 \% \mathrm{CI})$ & 14 & & 15 & & - & $100.0 \%$ & $7.50[3.53,11.47]$ \\
\hline \multicolumn{8}{|c|}{ Heterogeneity: not applicable } \\
\hline \multicolumn{8}{|c|}{ Test for overall effect: $Z=3.70(P=0.00021)$} \\
\hline \multicolumn{8}{|c|}{ Test for subgroup differences: Not applicable } \\
\hline
\end{tabular}

\section{Analysis I.I2. Comparison I SLT therapy versus no SLT therapy, Outcome I 2 F2u.}

Review: Speech and language therapy versus placebo or no intervention for speech problems in Parkinson's disease

Comparison: I SLT therapy versus no SLT therapy

Outcome: 12 F2u

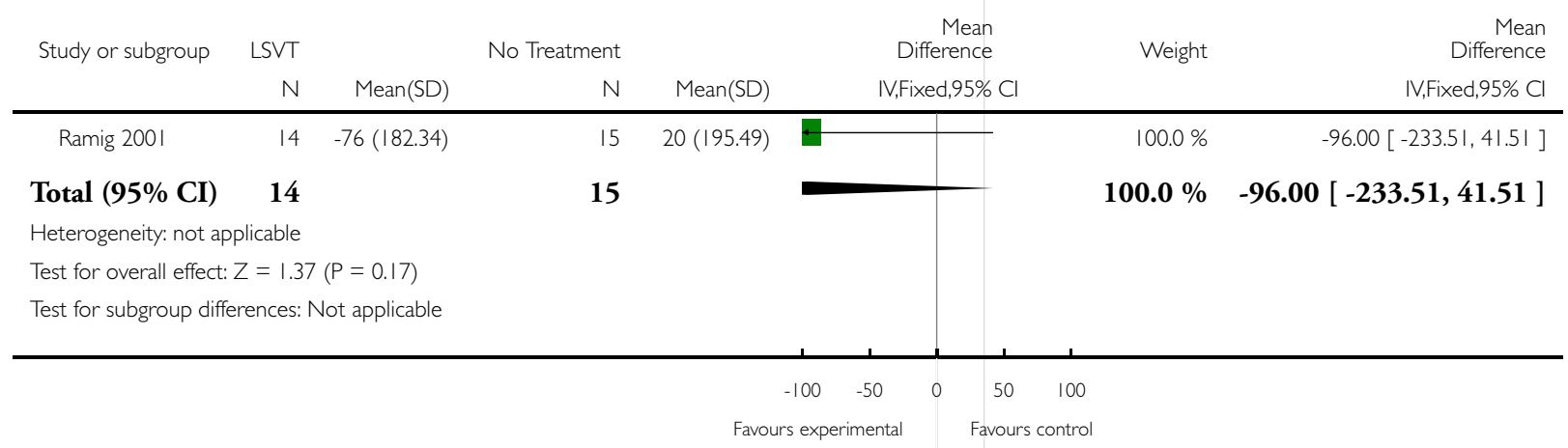




\section{Analysis I.I3. Comparison I SLT therapy versus no SLT therapy, Outcome I3 F2i/F2u.}

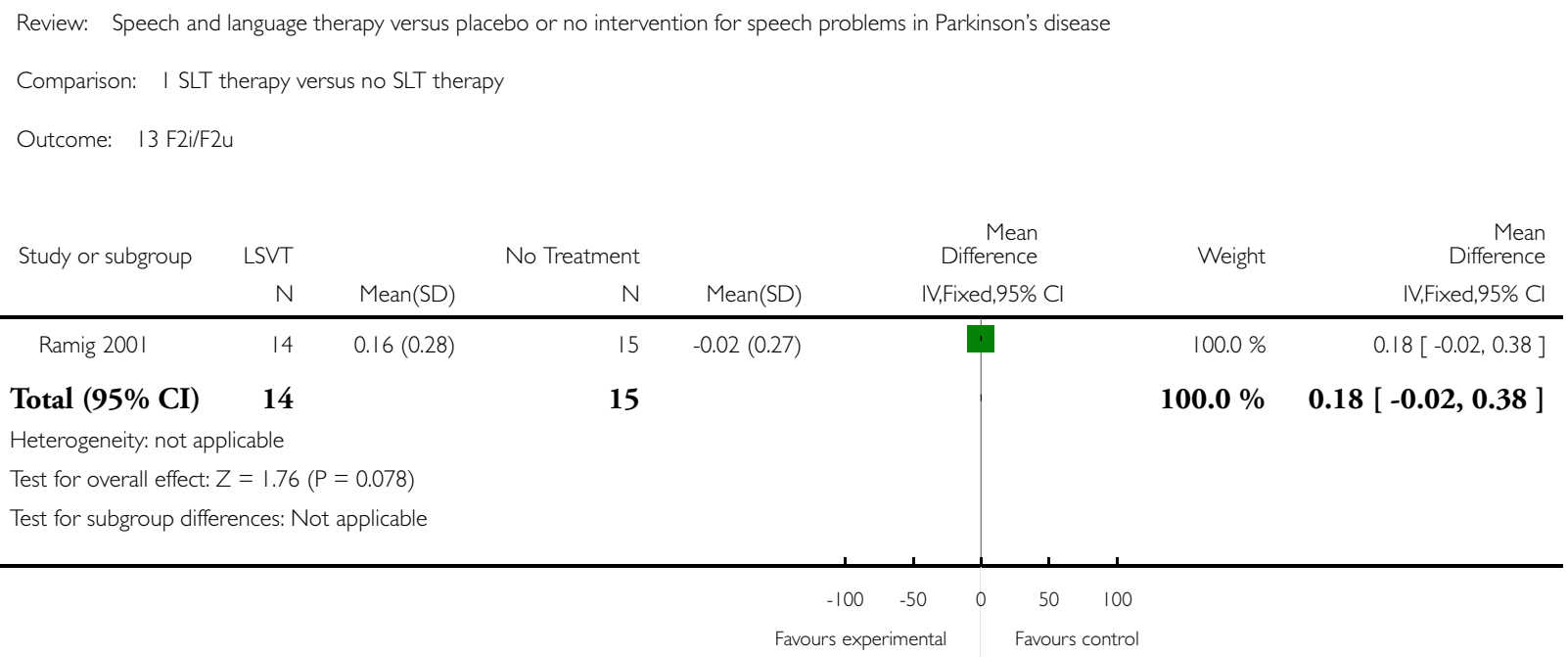

\section{Analysis I.14. Comparison I SLT therapy versus no SLT therapy, Outcome I4 Vowel goodness /i/.}

Review: Speech and language therapy versus placebo or no intervention for speech problems in Parkinson's disease

Comparison: I SLT therapy versus no SLT therapy

Outcome: 14 Vowel goodness/i/

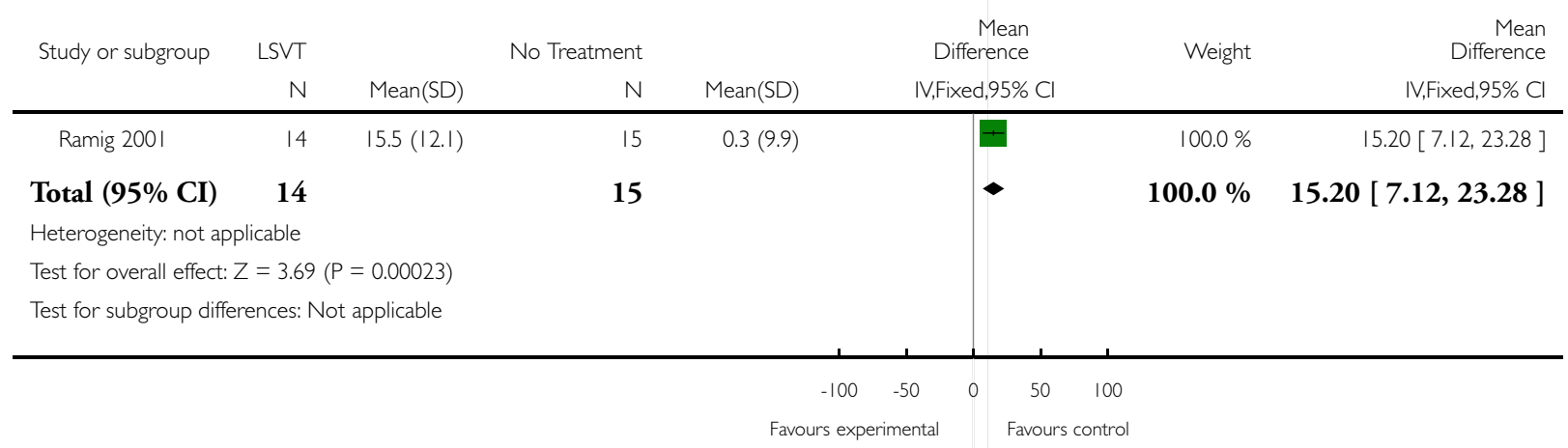


Analysis I.I5. Comparison I SLT therapy versus no SLT therapy, Outcome I5 Vowel goodness /u/.

Review: Speech and language therapy versus placebo or no intervention for speech problems in Parkinson's disease

Comparison: I SLT therapy versus no SLT therapy

Outcome: 15 Vowel goodness/u/

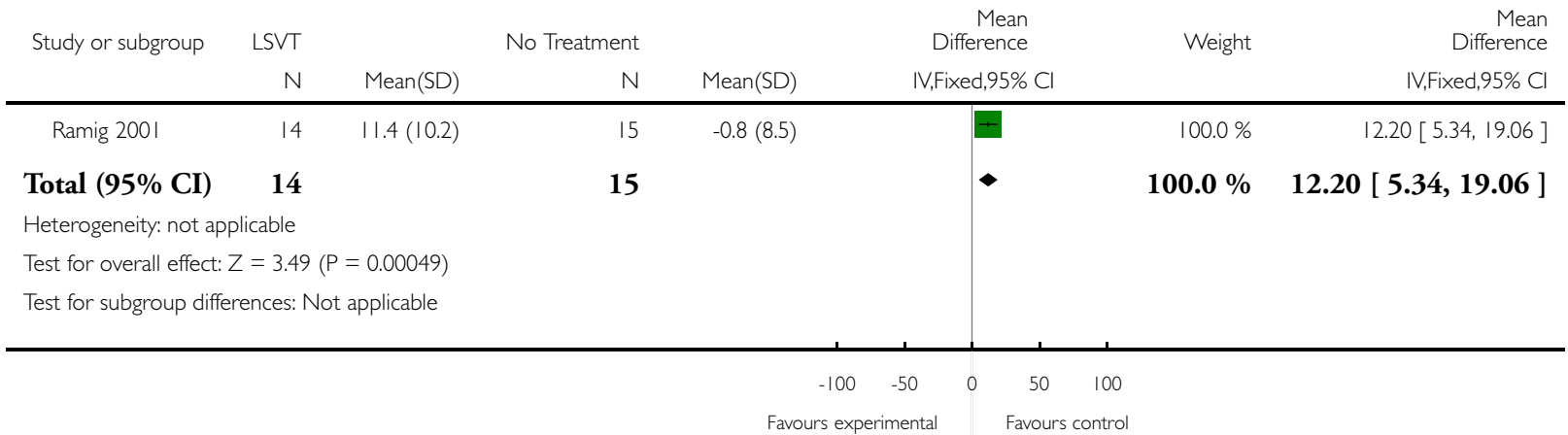

\section{Analysis I.I6. Comparison I SLT therapy versus no SLT therapy, Outcome 16 Vowel goodness /a/.}

Review: Speech and language therapy versus placebo or no intervention for speech problems in Parkinson's disease

Comparison: I SLT therapy versus no SLT therapy

Outcome: 16 Vowel goodness /a/

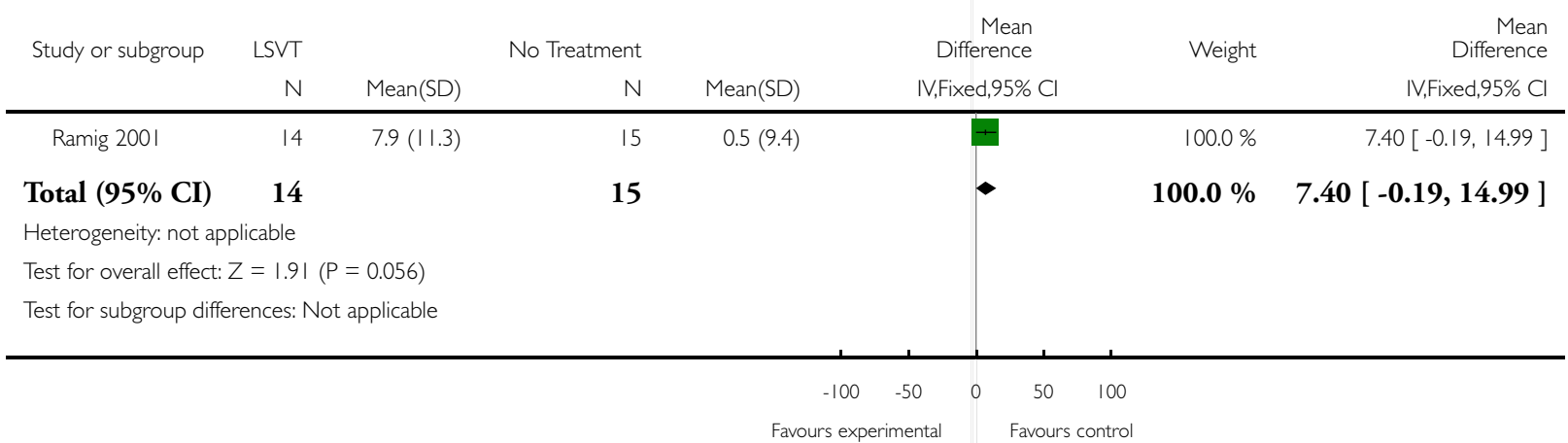


Analysis 2.I. Comparison 2 Therapy with visual feedback versus no treatment, Outcome I SPL monologue pre/post.

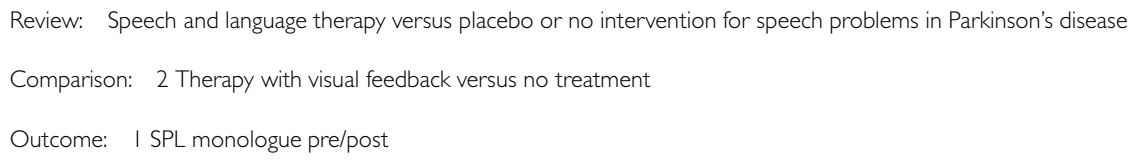

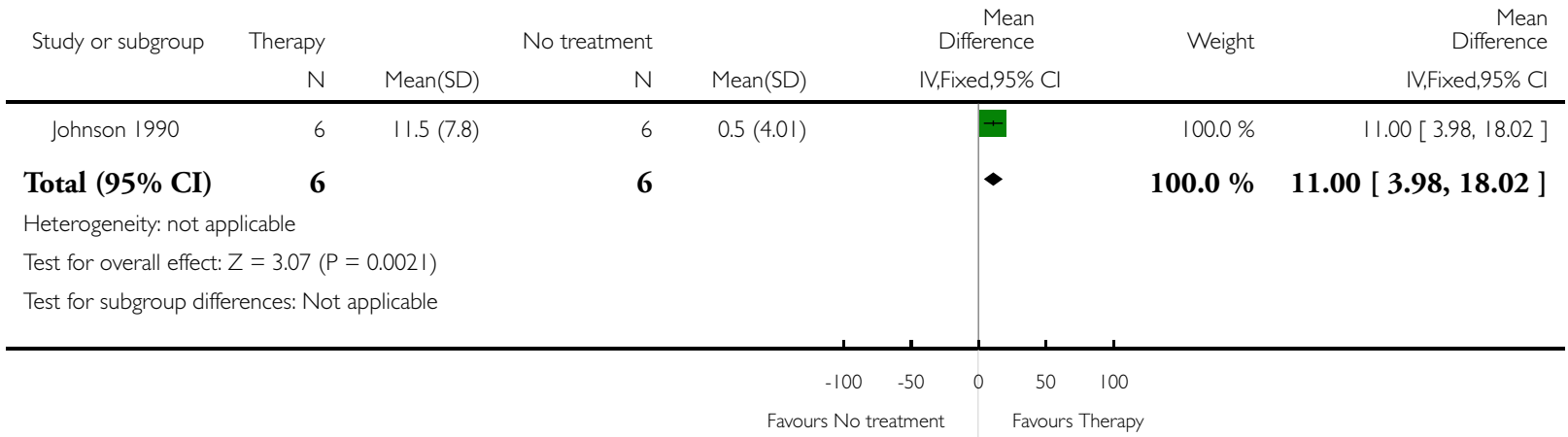

\section{Analysis 2.2. Comparison 2 Therapy with visual feedback versus no treatment, Outcome 2 SPL reading} pre/post.

Review: Speech and language therapy versus placebo or no intervention for speech problems in Parkinson's disease

Comparison: 2 Therapy with visual feedback versus no treatment

Outcome: 2 SPL reading pre/post

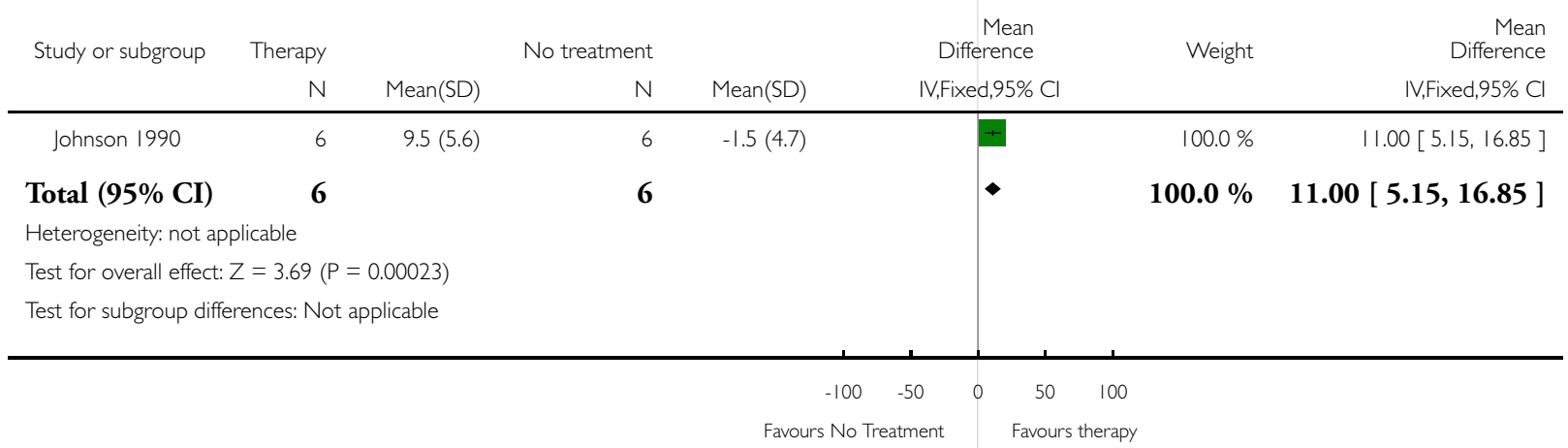




\section{Analysis 2.3. Comparison 2 Therapy with visual feedback versus no treatment, Outcome 3 Frenchay} dysarthria assessment.

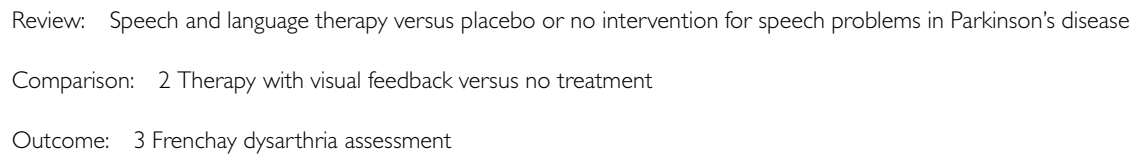

\begin{tabular}{|c|c|c|c|c|c|c|c|}
\hline \multirow[t]{2}{*}{ Study or subgroup } & \multirow{2}{*}{$\begin{array}{r}\text { Therapy } \\
\mathrm{N}\end{array}$} & \multicolumn{3}{|c|}{ No treatment } & \multirow{2}{*}{$\begin{array}{c}\text { Mean } \\
\text { Difference } \\
\text { IV,Fixed,95\% Cl }\end{array}$} & \multirow[t]{2}{*}{ Weight } & \multirow{2}{*}{$\begin{array}{r}\text { Mean } \\
\text { Difference } \\
\text { IV,Fixed,95\% Cl }\end{array}$} \\
\hline & & Mean(SD) & $\mathrm{N}$ & Mean(SD) & & & \\
\hline Johnson 1990 & 6 & $20(8.05)$ & 6 & $-9(17.4)$ & & $100.0 \%$ & $29.00[13.66,44.34]$ \\
\hline Total (95\% CI) & 6 & & 6 & & $<$ & $100.0 \%$ & $29.00[13.66,44.34]$ \\
\hline \multicolumn{8}{|c|}{ Heterogeneity: not applicable } \\
\hline \multicolumn{8}{|c|}{ Test for overall effect: $Z=3.7 \mathrm{I}(P=0.0002 \mathrm{I})$} \\
\hline \multicolumn{8}{|c|}{ Test for subgroup differences: Not applicable } \\
\hline
\end{tabular}

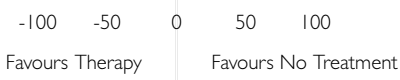

\section{Analysis 2.4. Comparison 2 Therapy with visual feedback versus no treatment, Outcome 4 Pitch range pre/post.}

Review: Speech and language therapy versus placebo or no intervention for speech problems in Parkinson's disease

Comparison: 2 Therapy with visual feedback versus no treatment

Outcome: 4 Pitch range pre/post

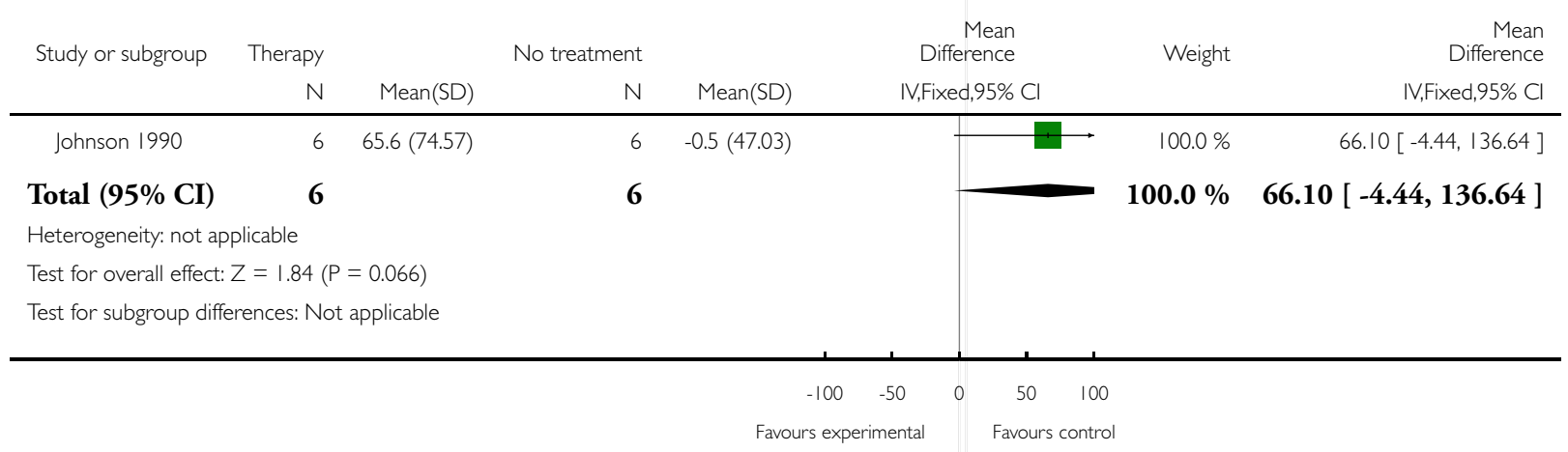


Analysis 2.5. Comparison 2 Therapy with visual feedback versus no treatment, Outcome 5 Volume range pre/post.

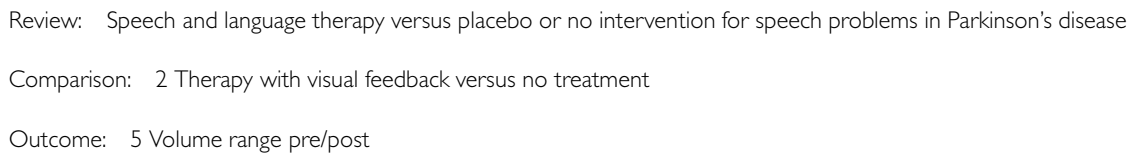

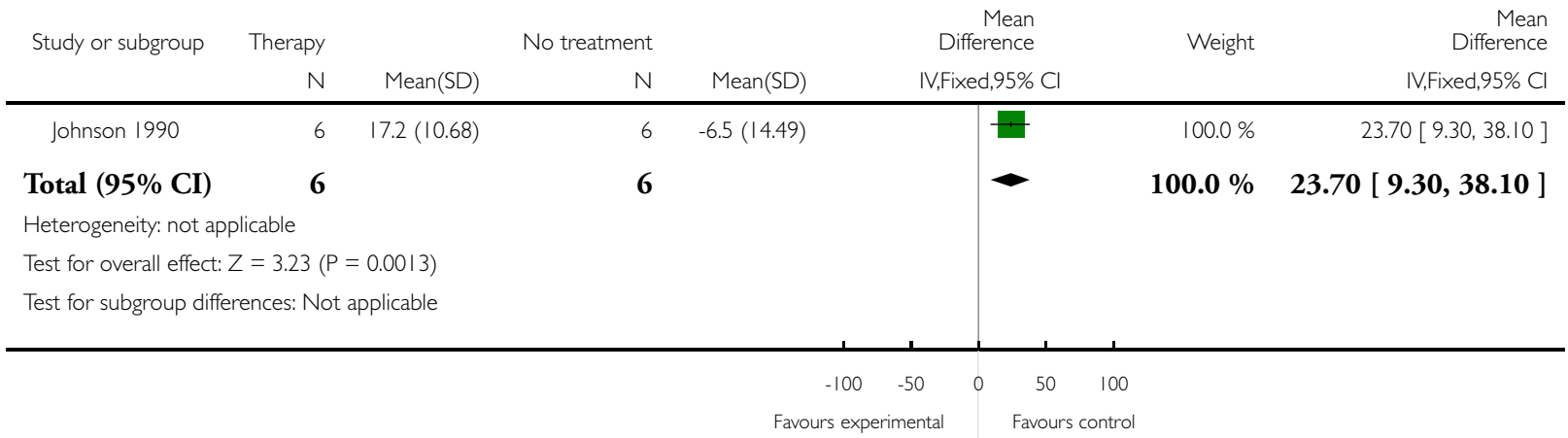

\section{Analysis 2.6. Comparison 2 Therapy with visual feedback versus no treatment, Outcome 6 Fundamental} frequency.

Review: Speech and language therapy versus placebo or no intervention for speech problems in Parkinson's disease

Comparison: 2 Therapy with visual feedback versus no treatment

Outcome: 6 Fundamental frequency

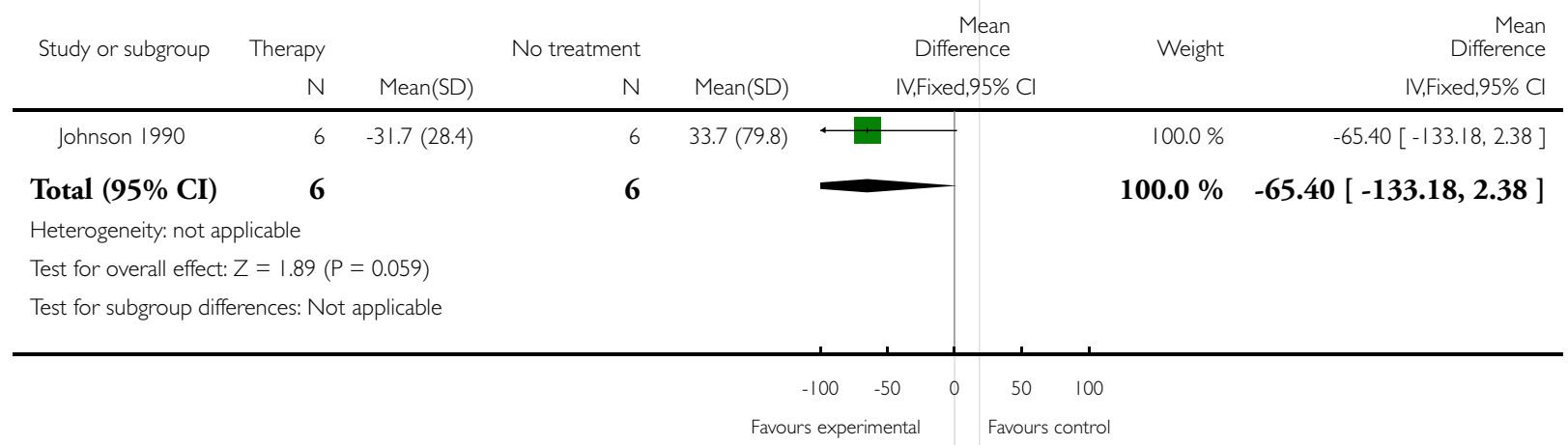


ADDITIONAL TABLES

Table 1. Glossary

\begin{tabular}{l|l}
\hline TERM & DEFINITION \\
\hline Amplitude & $\begin{array}{l}\text { The maximum absolute value of a periodically varying quantity. } \\
\text { For a sound wave, the maximum variation in pressure relative } \\
\text { to static conditions (e.g. atmospheric pressure). Small variations } \\
\text { produce weak (or quiet) sounds whilst large variations produce } \\
\text { strong (or loud) sounds. (See loudness below) }\end{array}$ \\
\hline
\end{tabular}

Articulation

The production of vowels and consonants using both the moving parts of the mouth (e.g. tongue and lips) and the fixed structure of the mouth (e.g. hard and soft palate). It does not involve the voice box

Concealment of allocation

The process used to conceal foreknowledge of group assignment, which should be seen as distinct from blinding. The allocation process should be impervious to any influence by the person making the allocation. Adequate methods of allocation concealment include: centralised randomisation schemes (telephone randomisation) or sequentially numbered opaque sealed envelopes

Decibel $(\mathrm{dB})$

A unit used to express relative difference in power or intensity, usually between two acoustic or electric signals, equal to ten times the common logarithm (i.e. base 10) of the ratio of the two levels. i.e. $10 \log 10(\mathrm{~W} 2 / \mathrm{W} 1)$ where $\mathrm{W} 1$ is the reference power level and $\mathrm{W} 2$ is the quantity being specified in $\mathrm{dB}$ relative to $\mathrm{W} 1$. It is commonplace to want to express in decibels, quantities that are related not to power, but power squared. Examples include sound pressure and voltage. In such cases the expression for the decibel level becomes $20 \log 10(\mathrm{p} 2 / \mathrm{p} 1)$. So that individual quantities can be specified, default reference values are defined for sound pressure $(20 \times 10 \mathrm{E}-6$ pascals), sound power (10E-6 watts) and sound intensity (10E-12 watts per square meter). For other quantities (e. g. voltage) a value of unity is often used implicitly. The reference level for sound pressure (corresponding to $0 \mathrm{~dB}$ ) was originally set as an approximation to the threshold of human hearing. A whisper has an intensity of $-30 \mathrm{~dB}$, normal speech $-60 \mathrm{~dB}$, a shout $-90 \mathrm{~dB}$ and a jet aircraft $-120 \mathrm{~dB}$

Dysarthria

Dysarthria is a collective name for a group of speech disorders resulting from disturbances in muscular control of the speech mechanism due to damage of the central nervous system. It designates problems in oral communication due to paralysis, weakness or incoordination of the speech musculature

Dysprosody Abnormal prosody (see prosody). Loss of the 'melody' of speech 
Table 1. Glossary (Continued)

Frequency
The number of complete cycles of a periodic process occurring per unit time. For sound waves this is the number of times the pressure variation cycle occurs in one second. The unit used to measure frequency is the hertz $(\mathrm{Hz})$ (see below)
Fundamental frequency (F0)

Fundamental frequency variability
The fundamental frequency is the inverse of the period (T0); i. e. F0 = 1/T0. For complex sounds such as speech, F0 will normally correspond to the frequency of the lowest harmonic. It is measured in hertz (see below). The aim of S\&LT is to increase the fundamental frequency of Parkinsonian speech as this leads to improved intelligibility. See also Pitch (see below)

The variation in fundamental frequency (see above) of speech. Measured as the standard deviation of F0 in hertz or semitones (STSD). The aim of S\&LT is to increase F0 variation and thus decrease the monotonicity of the patient's speech. See also Pitch

Hertz is the unit of frequency expressed in cycles (sound waves) per second
Hypophonia

Intelligibility
A breathy hoarseness to the speech.

Degree of clarity with which utterances are understood by average listeners. It is influenced by articulation, rate, fluency, vocal quality and intensity (see below)

The sound power propagating through a unit area of the sound field in a given direction. For example, the sound intensity of a point source radiating spherical waves and of a given sound power, will diminish as the distance from the source is increased, in proportion to the inverse of the square of this distance (1/ distance squared). It is a vector quantity since it specifies both a magnitude and direction, therefore direct measurement is not straightforward. Sound intensity has units of watts per square metre, but can also be expressed in decibels (see above). Sound intensity is related to the square of the sound pressure, but the exact relationship depends on the characteristics of the sound field

Intention-to-treat data analysis

Data are analysed according to the randomisation allocation, irrespective of protocol violations and withdrawals. Withdrawals, and therefore missing data points, are usually compensated for by using the last observation carried forward. Intention-to-treat analyses are favoured in assessments of effectiveness as they mirror the non-compliance and treatment changes that are likely to occur when the intervention is used in practice and because of the risk of attrition bias when participants are excluded from the analysis 
Table 1. Glossary (Continued)

\begin{tabular}{|l|l} 
Loudness & $\begin{array}{l}\text { Loudness is usually the subjective impression of the level of a } \\
\text { sound. However, in the text of this review we have also mentioned } \\
\text { 'objective' loudness. We define this as being loudness measured } \\
\text { mechanically, see intensity, sound pressure level and decibels. The } \\
\text { subjective loudness of a sound is defined as being relative to the } \\
\text { perceived loudness of a } 1000 \mathrm{~Hz} \text { tone generating a sound pres- } \\
\text { sure level of } 70 \mathrm{~dB} \text {. Loudness is influenced by frequency, level and } \\
\text { waveform shape and is governed by the physiology of the ear. It is } \\
\text { measured in units of phons. Typically, an increase in sound pres- } \\
\text { sure level of } 10 \mathrm{~dB} \text { results in a doubling of loudness. However, at } \\
\text { low levels of loudness, the increase is more like } 6 \mathrm{~dB} \text { for a corre- } \\
\text { sponding perceived change. Loudness is sometimes also referred } \\
\text { to as volume }\end{array}$ \\
\hline
\end{tabular}

A lack in variation of both loudness (see above) and pitch (see below)

Period (T0)

The length of each sound wave (cycle) in time is called the period of a waveform. It is equal to $1 /$ frequency

Per protocol data analysis

Data are analysed according to what therapy the patients received, rather than according to their randomised allocation. Withdrawals are removed from the analysis. This form of data analysis risks attrition bias

Phonation

Pitch

Prosody

Rainbow passage

Reference values for sound pressure, sound power and sound intensity (P0)
The mechanism of producing sounds with the vocal chords.

The perceptual correlate of frequency (see above). Normally, the pitch of a complex sound is a function of its fundamental frequency (see above). Equal steps in pitch are roughly equal to logarithmic steps in amplitude

Prosody is defined as that aspect of spoken language which consists in correct placing of pitch and stress on syllables and words. It is responsible for conveying subtle changes of meaning independently of words or grammatical order. In addition to this semantic role, it makes a major contribution to the emotional content of speech

A reading passage that is phonetically balanced and has all the vowel and consonant sounds present in the English language

So that individual quantities can be specified in terms of decibels, default reference values are defined for sound pressure $(20 \times 10 \mathrm{E}-$ 6 pascals), sound power (10E-6 watts) and sound intensity (10E12 watts per square meter). For other quantities (e.g. voltage) a value of unity is often used implicitly. The reference level for sound pressure (corresponding to $0 \mathrm{~dB}$ ) was originally set as an approximation to the threshold of human hearing. However this 
Table 1. Glossary (Continued)

equivalence has since been questioned

\begin{tabular}{l|l}
\hline Respiration & Breathing. \\
\hline Sound pressure and Sound pressure level (SPL) & $\begin{array}{l}\text { Sound pressure is the root mean square (r.m.s) variation in pres- } \\
\text { sure from the static value (e.g. the atmospheric pressure) and is } \\
\text { measured in pascals. The r.m.s variation in pressure from the static } \\
\text { value (e.g. the atmospheric pressure). Sound pressure is measured } \\
\text { in pascals, but can be expressed in decibels (see above), 20 log10 } \\
\text { (sound pressure/20x10E-6) whereupon it is referred to as sound } \\
\text { pressure level. Sound pressure is a scalar quantity and is therefore } \\
\text { relatively easy to measure: for example, a microphone responds } \\
\text { to sound pressure. The reference level for sound pressure (corre- } \\
\text { sponding to 0 dB) was originally set as an approximation to the } \\
\text { threshold of human hearing. However, this equivalence has since } \\
\text { been questioned }\end{array}$ \\
\hline Volume & \begin{tabular}{l} 
Equivalent to loudness (see above). \\
\hline
\end{tabular} \\
\hline
\end{tabular}

Table 2. Key characteristics of included studies

\begin{tabular}{|c|c|c|c|c|c|c|}
\hline Study & $\begin{array}{l}\text { Number of } \mathrm{Pa}- \\
\text { tients analysed }\end{array}$ & Mean Age & $\begin{array}{l}\text { Mean Hoehn \& } \\
\text { Yahr Score }\end{array}$ & $\begin{array}{l}\text { Duration of ther- } \\
\text { apy }\end{array}$ & $\begin{array}{l}\text { Location of ther- } \\
\text { apy sessions }\end{array}$ & Type of therapy \\
\hline Johnson 1990 & 12 & 64 & $\mathrm{n} / \mathrm{a}$ & 10 hours/4 weeks & Outpatients & $\begin{array}{l}\text { Prosodic exercises } \\
\text { with visual feed- } \\
\text { back }\end{array}$ \\
\hline Ramig 2001 & 29 & 70 & 2.7 & 16 hours/4 weeks & Outpatients & Phonatory effort \\
\hline Robertson 1984 & 22 & 63 & $\mathrm{n} / \mathrm{a}$ & 40 hours/2 weeks & Outpatients & $\begin{array}{l}\text { Respiration, loud- } \\
\text { ness, prosody with } \\
\text { visual feedback }\end{array}$ \\
\hline Total & 63 & & & & & \\
\hline
\end{tabular}

Table 3. Summary of results - Johnson 1990 \& Ramig 2000

\begin{tabular}{|c|c|c|c|c|c|}
\hline Subsection & Outcome & Study & n (SALT/Placebo) & $\begin{array}{l}\text { Mean difference Pre/ } \\
\text { Post (95\% CI lower, } \\
\text { upper, P value) }\end{array}$ & $\begin{array}{l}\text { Mean difference Pre/ } \\
6 \text { months ( } 95 \% \text { CI } \\
\text { lower, upper, P value) }\end{array}$ \\
\hline General assessments & $\begin{array}{l}\text { Fren- } \\
\text { chay Dysarthria As- } \\
\text { sessment }\end{array}$ & Johnson 1990 & $6 / 6$ & $\begin{array}{l}29.0(13.7,44.3,0 . \\
0002)\end{array}$ & \\
\hline
\end{tabular}


Table 3. Summary of results - Johnson 1990 \& Ramig 2000 (Continued)

\begin{tabular}{|c|c|c|c|c|c|}
\hline Loudness & Monologue (dB) & Johnson 1990 & $6 / 6$ & $\begin{array}{l}11.0(3.98,18.02,0 . \\
002)\end{array}$ & \\
\hline & & Ramig 2001 & $14 / 15$ & $5.4(2.6,8.2,0.0002)$ & $3.5(0.9,6.1,0.009)$ \\
\hline & $\begin{array}{l}\text { Describing Picture } \\
(\mathrm{dB})\end{array}$ & Ramig 2001 & $14 / 15$ & $5.2(2.0,8.4,0.001)$ & $4.2(1.1,7.3,0.008)$ \\
\hline & Reading (dB) & Johnson 1990 & $6 / 6$ & $\begin{array}{l}11.0 \quad(5.2, \quad 16.9, \quad 0 . \\
0002)\end{array}$ & \\
\hline & & Ramig 2001 & $14 / 15$ & $6.3(3.5,9.1,0.0007$ & $4.5(1.9,7.1,0.0007)$ \\
\hline & Prolonged 'a' (dB) & Ramig 2001 & $14 / 15$ & $\begin{array}{l}12.1(8.9,15.4,<0 \\
00001)\end{array}$ & $\begin{array}{l}9.4(6.2,12.6,<0 . \\
00001)\end{array}$ \\
\hline \multirow[t]{2}{*}{ Monotonicity } & $\begin{array}{l}\text { Maximum Pitch } \\
\text { Range }(\mathrm{Hz})\end{array}$ & Johnson 1990 & $6 / 6$ & $\begin{array}{l}66.0 \quad(-4.4,136.6,0 . \\
07)\end{array}$ & \\
\hline & $\begin{array}{l}\text { Maximum Volume } \\
\text { Range }(\mathrm{dB})\end{array}$ & Johnson 1990 & $6 / 6$ & $23.7(9.3,38.1,0.001)$ & \\
\hline Pitch & $\begin{array}{l}\text { Fundamental Fre- } \\
\text { quency of 'ah' }(\mathrm{Hz})\end{array}$ & Johnson 1990 & $6 / 6$ & $-65.4(-133,2,0.06)$ & \\
\hline
\end{tabular}

\section{APPENDICES}

\section{Appendix I. MEDLINE search strategy}

1. randomized controlled trial.pt.

2. controlled clinical trial.pt.

3. randomized.ab.

4. placebo.ab.

5. drug therapy.fs.

6. randomly.ab.

7. trial.ab.

8. groups.ab.

9. 1 or 2 or 3 or 3 or 4 or 5 or 6 or 7 or 8

10. exp animals/ not humans.sh.

11. 9 not 10

12. exp Parkinson disease/

13. Parkinson\$.tw.

14. 12 or 13

15. exp speech disorders/ 
16. exp articulation disorders/

17. dysarthr*.tw.

18. (speech or speak*).tw.

19. intelligib*.tw.

20. dysprod*.tw.

21. hypophoni*.tw.

22. monoton*.tw.

23. phon*.tw.

24. 15 or 16 or 17 or 18 or 19 or 20 or 21 or 22 or 23

25. exp "rehabilitation of speech and language disorders"/ or exp language therapy/ or exp myofunctional therapy/ or exp speech, alaryngeal/ or exp speech, esophageal/ or exp speech therapy/ or exp voice training/

26. ((speech or speak* or language or voice or vocal* or articulate* or sing*) adj3 (task* or therap* or treat* or train* or councel* or intervention* or exercise* or drill)).tw.

27. (Silverman* or LSVT).tw.

28. 25 or 26 or 27

29. $\quad 11$ and 14 and 24 and 28

30. 11 and 14 and 28

31. 29 or 30

\section{WHAT'S NEW}

Last assessed as up-to-date: 11 April 2011.

\begin{tabular}{ll|l}
\hline Date & Event & Description \\
\hline 9 July 2012 & New citation required but conclusions have not changed & New citation \\
\hline 9 July 2012 & New search has been performed & $\begin{array}{l}\text { Searches have been rerun and new studies were incorpo- } \\
\text { rated }\end{array}$ \\
\hline
\end{tabular}

\section{H I S T O R Y}

Protocol first published: Issue 4, 2000

Review first published: Issue 2, 2001

\begin{tabular}{lll}
\hline Date & Event & Description \\
\hline 6 September 2011 & $\begin{array}{l}\text { New citation required but conclusions have not } \\
\text { changed }\end{array}$ & $\begin{array}{l}\text { Full search and update, new citation added, conclu- } \\
\text { sions unchanged }\end{array}$ \\
\hline 13 November 2008 & Amended & Converted to new review format. \\
\hline 9 February 2001 & New citation required and conclusions have changed & Substantive amendment \\
\hline
\end{tabular}




\section{CONTRIBUTIONSOFAUTHORS}

C Herd carried out the majority of the searching for eligible studies. C Herd and C Tomlinson extracted the data from the included studies. All reviewers were involved in the writing of the review. C Herd was the primary updating author and KHO Deane was the original author.

\section{DECLARATIONSOF INTEREST}

Authors C Herd, C Smith, MC Brady, C Sackley and CE Clarke are part of a team performing a pilot trial comparing LSVT versus NHS SLT versus attention control (PD COMM). The views expressed here are those of the authors and not necessarily those of the Chief Scientist Office.

\section{SOURCES OF SUPPORT}

\section{Internal sources}

- City Hospital NHS Trust, UK.

\section{External sources}

- UK Cochrane Centre, UK.

- NHS Research and Development Programme for People with Physical and Complex Disabilities; Project PCD2/A1/250, UK.

- Conference grant from The Royal Society, UK.

- Conference grant from Pharmacia Upjohn, UK.

- Chief Scientist Office (CSO), UK.

\section{INDEX TERMS}

\section{Medical Subject Headings (MeSH)}

*Language Therapy; *Speech Therapy; Dysarthria [etiology; *therapy]; Parkinson Disease [*complications]; Randomized Controlled Trials as Topic; Speech Intelligibility; Watchful Waiting

\section{MeSH check words}

Humans 